\title{
Apelin (APLN) regulates progesterone secretion and oocyte maturation in bovine ovarian cells
}

\author{
J Roche ${ }^{1,2,3}$, C Ramé ${ }^{1,2,3}$, M Reverchon ${ }^{1,2,3}$, N Mellouk1,2,3, A Rak ${ }^{4}$, P Froment ${ }^{1,2,3}$ and \\ J Dupont ${ }^{1,2,3}$
}

${ }^{1}$ INRA, UMR85 Physiologie de la Reproduction et des Comportements, Nouzilly, France, ${ }^{2}$ CNRS, UMR7247 Physiologie de la Reproduction et des Comportements, Nouzilly, France, ${ }^{3}$ Université François Rabelais de Tours, Tours, France and ${ }^{4}$ Department of Physiology and Toxicology of Reproduction, Institute of Zoology, Jagiellonian University of Krakow, Krakow, Poland

Correspondence should be addressed to J Dupont; Email: jdupont@tours.fr

\begin{abstract}
APLN and its G-protein coupled receptor APLNR are expressed in the bovine ovary. However their role in granulosa cells and oocytes is unknown. Here, we studied their expression in bovine ovarian cells and investigated their regulation in cultured luteinizing granulosa cells in response to IGF1 and FSH. We determined the effect and the molecular mechanism of APLN (isoforms 17 and 13) on bovine granulosa cell progesterone secretion and on oocyte maturation. By RT-qPCR and immunoblot, we showed that the expression of both APLN and APLNR in granulosa and oocytes significantly increased with ovarian follicles size whereas it was similar in theca interstitial cells. In vitro, in unstimulated luteinizing bovine granulosa cells and in response to IGF1 (10 $\left.{ }^{-8} \mathrm{M}\right)$ but not to FSH $\left(10^{-8} \mathrm{M}\right)$, we observed that APLN $(-17$ and -13$)\left(10^{-9} \mathrm{M}\right)$ increased progesterone production; this was abolished in response to the APLNR antagonist ML221. These latter effects were dependent on the MAPK ERK1/2 kinase. Furthermore, we showed that APLN $(-17$ and -13$)\left(10^{-9} \mathrm{M}\right)$ increased cell proliferation through AKT signaling. Conversely, the addition of APLN-13 and APLN-17 to in vitro maturation medium containing IGF1 $\left(10^{-8} \mathrm{M}\right)$ but not FSH $\left(10^{-8} \mathrm{M}\right)$ arrested most oocytes at the germinal vesicle stage, which was associated with a decrease in progesterone secretion, an inhibition in MAPK ERK1/2 phosphorylation and an increase in PRKA phosphorylation in oocytes. Thus, APLN can increase progesterone secretion and cell proliferation in bovine luteinizing granulosa cells in vitro, while it blocks meiotic progression at the germinal vesicle stage during bovine oocyte in vitro maturation. Reproduction (2017) 153 589-603
\end{abstract}

\section{Introduction}

Apelin (APLN) is a recently described adipokine mainly produced by adipose tissue. It is translated as a 77-amino acid prepropeptide precursor and cleaved into shorter peptides (e.g., APLN-13, APLN17 and -36) (Hosoya et al. 2000). However APLN-13 displays much greater biological potency than APLN36 (Tatemoto et al. 1998, Kawamata et al. 2001). APLN peptides are ligands for the cognate G-protein coupled receptor APLNR that was first defined as being analogous to the angiotensin II type 1 receptor (AT1) (O'Dowd et al. 1993). APLN, signaling through APLNR, can modulate numerous intracellular signaling cascades including MAPKs (Bai et al. 2008), AKT (Liu et al. 2015) and PRKA (Yang et al. 2016). APLN/APLNR mRNA and protein have a wide tissue distribution in the central nervous system and in the peripheral organs, including the heart, lung, vessels, and adipose tissue, as well as the testis, ovary (Habata et al. 1999) and placenta in human and rodents. The multiple expression sites of the
APLN/APLNR system indicate that it may play pivotal roles in various physiological functions. Indeed, APLN is involved in the regulation of the cardiovascular system (Wu et al. 2014), energy metabolism (Bertrand et al. 2015), food intake (Lv et al. 2012), angiogenesis (Zhang et al. 2016) and neuroendocrine functions (Newson et al. 2013). APLN and APLNR have also been identified in the gonads and in the arcuate, supraoptic and paraventricular hypothalamic nuclei, suggesting their roles in the control of reproduction (Sandal et al. 2015).

Our laboratory has recently described APLN and APLNR in human ovarian cells (Roche et al. 2016). In primary human granulosa cells, we have shown that APLN increases IGF1-induced steroidogenesis through an increase in 3-beta-hydroxysteroid dehydrogenase protein expression and activation of the MAPK ERK $1 / 2$ and AKT pathways (Roche et al. 2016). In the rat, a recent study showed that APLN can promote the proliferation of granulosa cells and inhibit apoptosis via PI3/AKT signaling (Shuang et al. 2016). In the male rat, 
an intracerebroventricular injection of APLN-13 reduces testosterone secretion by inhibiting luteinizing hormone (LH) release, suggesting a role for APLN in the control of reproductive functions at both the pituitary and gonad level (Sandal et al. 2015). Furthermore, recent data demonstrated that an intraperitoneal injection of APLN-13 in male rats decreases serum testosterone, $\mathrm{LH}$ and follicle-stimulating hormone (FSH) levels (Tekin et al. 2016). In bovine species, it has been shown that APLN and APLNR mRNAs are expressed in the bovine follicle and corpus luteum (CL) (Shirasuna et al. 2008, Schilffarth et al. 2009, Shimizu et al. 2009). In the $\mathrm{CL}$, expression decreases at the end of the luteal phase and during CL regression (Shirasuna et al. 2008, Schilffarth et al. 2009, Shimizu et al. 2009). Thus, the APLN/APLNR system could be involved in vascular establishment, maturation and maintenance in the $\mathrm{CL}$ during the estrous cycle (Shirasuna et al. 2008). In the bovine follicle, APLNR is present in bovine granulosa cells where its expression is increased by progesterone (Shimizu et al. 2009). In mature follicles, the APLN/ APLNR system is thought to play a crucial role during follicle selection and dominance in the bovine species (Shimizu et al. 2009). However the presence and the role of the APLN/APLNR system have never been investigated in bovine granulosa cells and oocytes.

The main objectives of the present study were to investigate the regulation of APLN and APLNR expression and the effects of APLN on progesterone production and cell proliferation as well as the associated molecular mechanisms in primary bovine granulosa cells. Furthermore, we analyzed the effect of APLN on in vitro bovine oocyte maturation.

\section{Materials and methods}

\section{Ethics}

All experimental protocols were approved by an ethics committee ('Comité d'Ethique en Expérimentation Animale Val de Loire'; CEEA VdL, protocol registered as n 2012-09-6), and were carried out in accordance with the guidelines of the French Council for Animal Care.

\section{Hormones and reagents}

Recombinant human IGF1 was obtained from Sigma. Purified ovine FSH (lot no. AFP-7028D, 4453IU/mg, FSH activity $=175 \times$ activity of (oFSH-S1)) used for culture treatment was a gift from NIDDK, National Hormone Pituitary Program, Bethesda, MD, USA. Recombinant human APLN-13 (rh APLN-13) and 17 (rh APLN-17) were purchased from Abcam and R\&D Systems respectively. Thymidine methyl- $\mathrm{H}^{3}$ was obtained from Amersham Life Science. The pharmacological inhibitors U0126 (1,4-diamino-2,3-dicyano-1,4-bis(oaminophenylmercapto)butadiene monoethanolate), LY294002 (2-morpholin-4-yl-8-phenylchromen-4-one), $\quad$ SB202190 (4-(4-fluorophenyl)-2-(4-hydroxyphenyl)-5-(4-pyridyl)-1H- imidazole) and Compound C (6-[4-(2-piperidin-1-yl-ethoxy)phenyl]-3-pyridin-4-yl-pyrrazolo[1,5-a]-pyrimidine) were obtained from Millipore. The APLNR antagonist, ML221, was purchased from R\&D Systems.

\section{Antibodies}

Rabbit polyclonal antibodies to APLN and APLNR were purchased from Antibodies-online and Sigma respectively. Rabbit polyclonal antibodies to phospho-MAPK ERK $1 / 2$ (Thr202/Tyr204), phospho-p38 (Thr180/Tyr182), phosphoPRKA (Thr172) and total PRKA were obtained from Ozyme (Montigny Le Bretonneux, France). Mouse monoclonal antibodies to VINCULIN (VCL) were obtained from Sigma. Rabbit polyclonal antibodies recognizing total ERK2 (C14), phospho-AKT (Ser 473) and total MAPK P38 were purchased from Santa Cruz Biotechnology. All antibodies were used at 1:1000 for Western blotting.

\section{Collection of bovine follicles and primary culture of bovine granulosa cells}

Bovine ovaries were obtained from adult cows collected at a local slaughterhouse and transported aseptically before dissection. Antral follicles were designated into three different groups based on diameter $(3-5 \mathrm{~mm}$, small (SF); $6-9 \mathrm{~mm}$, medium (MF); and $>9 \mathrm{~mm}$, large (LF)). In each group of follicles, granulosa (GCs), theca interstitial cells and oocyte for mRNA and protein extraction were collected and immediately frozen in liquid nitrogen and stored at $-80^{\circ} \mathrm{C}$. For culture, GCs were recovered from small antral follicles (SF) in modified McCoy's $5 \mathrm{~A}$ medium followed by $5 \mathrm{~min}$ of centrifugation. Cells were washed, counted in a hemocytometer and cultured in McCoy's 5A supplemented with $20 \mathrm{mmol} / \mathrm{L}$ HEPES, penicillin $(100 \mathrm{U} / \mathrm{mL})$, streptomycin $(100 \mathrm{mg} / \mathrm{L})$, L-glutamine $(3 \mathrm{mmol} / \mathrm{L})$, $0.1 \% \mathrm{BSA}, 5 \mathrm{mg} / \mathrm{L}$ transferrin, $20 \mathrm{mg} / \mathrm{L}$ selenium, $0.1 \mu \mathrm{mol} / \mathrm{L}$ androstenedione and $10 \%$ fetal bovine serum (FBS, PAA Laboratories, les Mureaux, France). Approximately $4 \times 10^{5}$ viable cells were seeded in each plastic multiwell containing $1 \mathrm{~mL}$ of medium. After $24 \mathrm{~h}$ of culture, cells were starved with McCoy's $5 \mathrm{~A}$ medium containing $1 \%$ of FBS overnight and then incubated in fresh culture medium with or without the test reagent for the appropriate period of time. All cultures were performed in a water-saturated atmosphere of $95 \%$ air $/ 5 \%$ $\mathrm{CO}_{2}$ at $37^{\circ} \mathrm{C}$.

\section{RNA isolation and RT-PCR}

As described previously (Reverchon et al. 2014), total RNA was extracted by using Trizol reagent according to the manufacturer's procedure (Sigma Aldrich). Reverse transcription (RT) and polymerase chain reaction (PCR) were then carried out. RT was performed on RNA amounts corresponding to 10 oocytes or on $1 \mu \mathrm{g}$ total RNA from granulosa or theca interstitial cells. Briefly, $1 \mu$ g total RNA was reverse transcribed for $1 \mathrm{~h}$ at $37^{\circ} \mathrm{C}$ in a final reaction volume of $20 \mu \mathrm{L}$ containing $50 \mathrm{mM}$ Tris- $\mathrm{HCl}(\mathrm{pH} 8.3), 75 \mathrm{mM} \mathrm{KCl}$, $3 \mathrm{mM} \mathrm{MgCl} 2,200 \mu \mathrm{M}$ each deoxynucleotide triphosphate (Amersham), $50 \mathrm{pmol}$ oligo(dT) 15, $5 \mathrm{U}$ ribonuclease inhibitor 
and $15 \cup$ MMLV reverse transcriptase; $2 \mu \mathrm{M}$ each set of specific primers were used. These specific primer pairs were for APLN (forward 5'-AAGGCACCATCCGATACCTG-3' and reverse 5'-ATGGGACCCTTGTGGGAGA-3') and APLNR $(A P J)$ (forward 5'-TCTGGGCCACCTACACCTAT-3' and reverse $5^{\prime}$-ACGCTGGCGTACATGTTG-3'). The PCR conditions were DNA denaturation at $95^{\circ} \mathrm{C}$ for $5 \mathrm{~min}, 95^{\circ} \mathrm{C}$ for $1 \mathrm{~min}, 58^{\circ} \mathrm{C}$ for $1 \mathrm{~min}$ and $72^{\circ} \mathrm{C}$ min for 35 cycles before a final extension at $72{ }^{\circ} \mathrm{C}$ for $10 \mathrm{~min}$. For this, $2 \mu \mathrm{L}$ RT reaction mixture was used in a $25 \mu \mathrm{L}$ final volume containing $10 \mathrm{mM}$ Tris- $\mathrm{HCl}(\mathrm{pH} 9.0)$, $50 \mathrm{mM} \mathrm{KCl}, 1.5 \mathrm{mM} \mathrm{MgCl}, 200 \mathrm{mM}$ each deoxynucleotide triphosphate, $10 \mathrm{pmol}$ each primer and $1 \mathrm{U}$ Taq polymerase. The results were viewed on a $1.5 \%$ agarose gel stained with ethidium bromide and the amplified DNA was extracted and sequenced by the Genome Express (Meylan, France). Consumables for RT-PCR were obtained from Sigma, and Moloney Murine Leukemia Virus reverse transcriptase and the RNase inhibitor were obtained from Promega.

\section{Real-time polymerase chain reaction}

After reverse transcription, the bovine cDNAs of ovarian cells were diluted 1:5. Real-time PCR was performed in a $20 \mu \mathrm{L}$ final volume containing $10 \mu \mathrm{L}$ iQ SYBR Green supermix (Bio-Rad), $0.25 \mu \mathrm{L}$ each primer $(10 \mu \mathrm{M}), 4.5 \mu \mathrm{L}$ water and $5 \mu \mathrm{L}$ template. The cDNA templates were amplified and detected with the MYIQ Cycler real-time PCR system (Bio-Rad) using the following protocol: 1 cycle for $5 \mathrm{~min}$ at $95^{\circ} \mathrm{C}$ to denature the sample and then 40 cycles, $1 \mathrm{~min}$ at $95^{\circ} \mathrm{C}$ for denaturation, $1 \mathrm{~min}$ at $60^{\circ} \mathrm{C}$ for hybridization, $1 \mathrm{~min}$ at $72^{\circ} \mathrm{C}$ for stretching and finally 1 cycle for $5 \mathrm{~min}$ at $72^{\circ} \mathrm{C}$ for final elongation. Gene expression was normalized using the geometric mean of three housekeeping genes (ACTB, RPL19 and PPIA) with stable expression under our conditions (data not shown). The description of the different primers is: ACTB (forward 5'-GCGGGAAATCGTGCGTGACATT-3' and reverse 5'-GATGGAGTTGAAGGTAGTTTCGTG-3'), RPL19 (forward 5'-gggcataggtaagcggaagg-3' and reverse 5'-TCAGGTACAGGCTGCCGA-3') and PPIA (forward 5'-AGCATGTGGTGTTTGGCAAA-3' and reverse 5'-TCGAGTTGTCCACAGTCAGC-3'). For APLN and APLNR, the same primers described in the previous paragraph were used. The normalized values of relative expression ( $R$ ) were calculated according to the following equation: $\mathrm{R}=\left(E_{\text {Gene }}^{- \text {Ct Gene }}\right) /\left(\right.$ geometric mean $\left.\left(E_{\text {Ppia }}^{- \text {Ct Ppia }} ; E_{\text {Rpl19 }}^{-C t ~ R p l 19}\right)\right)$, where $\mathrm{Ct}$ is the cycle threshold and $E$ is the PCR efficiency for each primer pair. The specificity of the amplified fragment sequence was assessed by Beckman Coulter Genomics (Essex, United Kingdom). The efficiency was between 1.7 and 2 .

\section{Protein extraction and Western blot}

Bovine ovarian cells were homogenized as previously described (Tosca et al. 2007a,b). Lysates were incubated on ice for $30 \mathrm{~min}$ before centrifugation at $12,000 \mathrm{~g}$ for $20 \mathrm{~min}$ at $4^{\circ} \mathrm{C}$. The pellet was eliminated and the samples were stored at $-80^{\circ} \mathrm{C}$. The protein concentration for each condition was measured using a BCA protein assay. Samples were denatured and submitted to electrophoresis on $12 \%$ SDS-polyacrylamide gels at 90 volts before being transferred onto nitrocellulose membranes (Schleicher and Schuell, Ecquevilly, France). Then, the membranes were blocked for 30 min with TBS-Tween-milk $5 \%$ and incubated with specific primary antibodies (dilution $1 / 1000$ ) for $16 \mathrm{~h}$ at $4^{\circ} \mathrm{C}$. After several washes, membranes were incubated for $1 \mathrm{~h} 30 \mathrm{~min}$ with the secondary antibodies conjugated with HRP anti-rabbit or anti-mouse IgG at a final dilution of 1:5000. Proteins were revealed by enhanced chemiluminescence (Western Lightning Plus-ECL, Perkin Elmer) using a G:Box Syngene (Ozyme) with GeneSnap software (release 7.09.17). Quantification was performed with GeneTools software (release 4.01.02).

\section{Thymidine incorporation into granulosa cells}

Primary bovine granulosa cells were cultured for $24 \mathrm{~h}$ in McCoy's 5A medium and 10\% fetal bovine serum (FBS). Cells were plated in 24 -well plates $\left(2 \times 10^{5}\right.$ viable cells/well) and four replicates were tested for each experimental condition (APLN and/or IGF1 in the absence or in the presence of ML221) for each culture. After several washes and overnight serum starvation, cells were cultured for $24 \mathrm{~h}$ with $1 \mu \mathrm{Ci}$ / $\mu \mathrm{L}\left[{ }^{3} \mathrm{H}\right]$ thymidine (Amersham Life Science) in the presence or absence of APLN 13 or APLN 17 and/or IGF1 $\left(10^{-8} \mathrm{M}\right)$. Thymidine was then removed with PBS and cells were fixed with cold $50 \%$ trichloroacetic acid for $15 \mathrm{~min}$ on ice. Finally, cells were lysed using $0.5 \mathrm{~N} \mathrm{NaOH}$ and the radioactivity was counted in a $\beta$-photomultiplier by adding scintillation fluid (Packard Bioscience).

\section{Progesterone ELISA assay}

Progesterone concentrations were measured in serum-free medium from primary bovine granulosa cells after $48 \mathrm{~h}$ of culture using an EIA protocol as previously described (Canepa et al. 2008). Cells were plated in 48-well plates $\left(10^{5}\right.$ viable cells/well) and six replicates were tested for each experimental condition ( $r$ APLN-13 or -17, IGF1) in the absence or presence of ML221 for each culture. The results were expressed as the concentration of the steroid $(\mathrm{ng} / \mathrm{mL}$ ) according to the protein concentration in each well. The intra- and inter-assay coefficients of variation for progesterone were less than $10 \%$ and $11 \%$ respectively. Results are given as mean \pm S.E.M. and are representative of six independent cultures with each condition in quadruplicate.

\section{Bovine oocyte collection and in vitro maturation}

Bovine ovaries were collected from a slaughterhouse in sterile $\mathrm{NaCl}$ solution and maintained at $37^{\circ} \mathrm{C}$ until aspiration. The cumulus-oocyte complexes (COCs) were aspirated from follicles 3 to $8 \mathrm{~mm}$ in diameter using an 18-G needle connected to a sterile test tube and to a vacuum line $(100 \mathrm{mmHg})$, as previously described (Reverchon et al. 2014). COCs were then selected under a dissecting microscope. Expanded or nonintact COCs were eliminated: only intact COCs were washed in TCM HEPES 199 (Sigma) supplemented with BSA (0.4\%) and gentamicin $(2.5 \mathrm{~mL} / \mathrm{L})$ under mineral oil (Sigma). The 
COCs were cultured in TCM 199 (Sigma) with BSA $(4 \mathrm{mg} / \mathrm{mL}$ ) supplemented or not with APLN-13 or APLN-17 $\left(10^{-9} \mathrm{M}\right)$ in the absence or in the presence of IGF-1 $\left(10^{-8} \mathrm{M}\right)$ or FSH $\left(10^{-8} \mathrm{M}\right)$ for $22 \mathrm{~h}$ at $39^{\circ} \mathrm{C}$ in $5 \% \mathrm{CO}_{2}$ in air with saturated humidity. Each oocyte group contained at least 25 oocytes. After maturation, COCs were denuded by pipetting with $0.5 \%$ hyaluronidase (Sigma). Collected oocyte and cumulus cells were then frozen at $-80^{\circ} \mathrm{C}$.

\section{Statistical analysis}

All experimental data are presented as the mean \pm S.E.M. One or two-way analysis of variance was used to test differences. $P<0.05$ was considered to be statistically significant. StatView software was used for all statistical tests.

\section{Results}

\section{Expression of APLN and APLNR in different sizes of bovine follicles}

Using real-time PCR of different sizes of ovarian follicles (SF, MF and LF) we showed that mRNA expression of both APLN and APLNR in granulosa and oocytes significantly increased with ovarian follicles size whereas it was similar in theca interstitial cells (Fig. 1A, B and C). These data were confirmed by immunoblotting (Fig. 1D, E and F). Thus, APLN and its receptor, APLNR, are present in different bovine ovarian follicular cells (granulosa and theca interstitial cells and oocytes). Furthermore, their expression is differently regulated with the size of follicles.
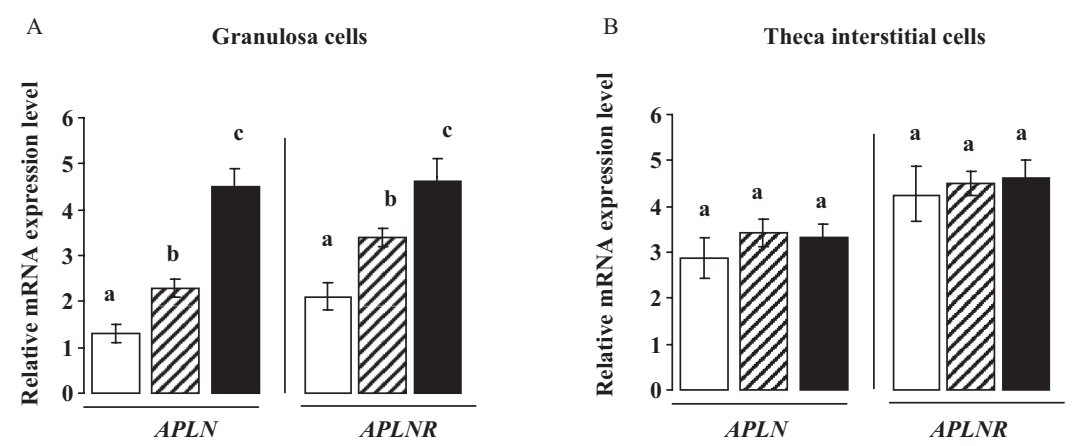

C Oocytes

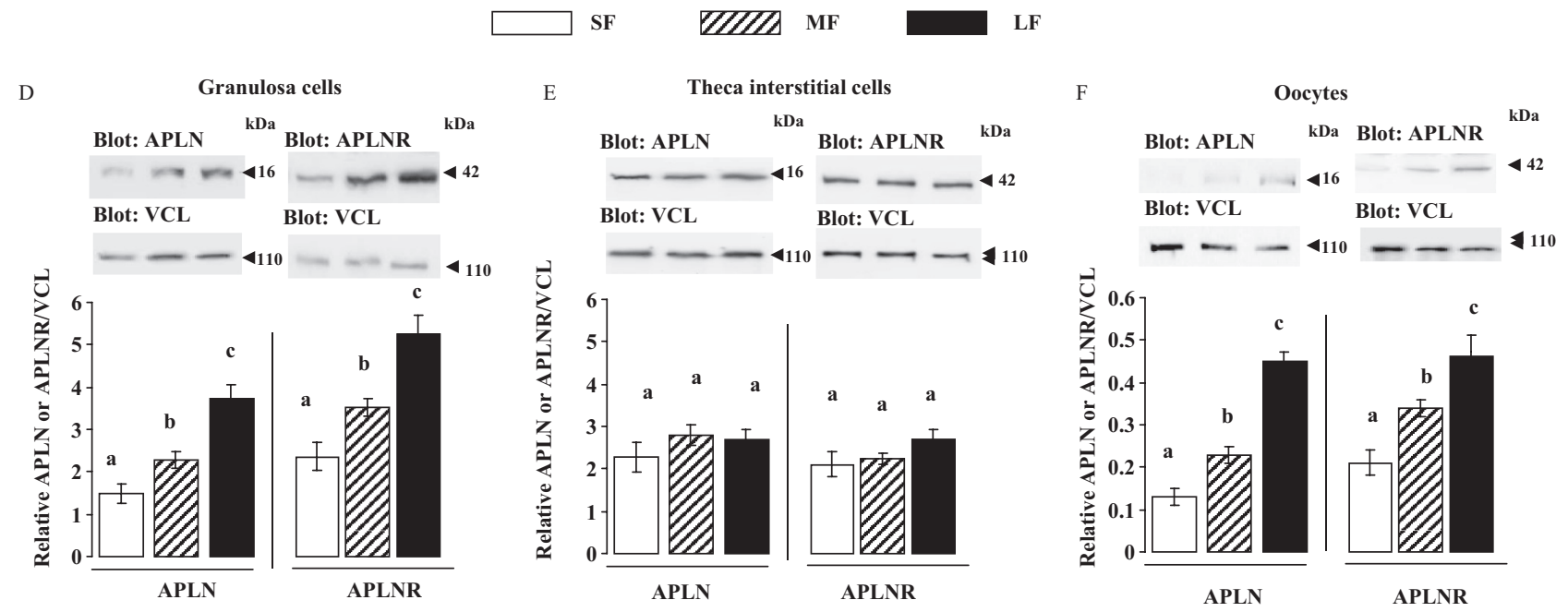

Figure 1 APLN and APLNR expression in granulosa, theca interstitial cells and oocytes from small (SF), medium (MF) and large (LF) ovarian bovine follicles. (A, B, C and C) APLN and APLNR mRNA expression was measured by quantitative RT-PCR in different ovarian cells from SF, MF and LF as described in 'Materials and methods' section. (D, E and F) APLN and APLNR protein levels by immunoblotting in granulosa, theca interstitial cells and oocytes from SF, LF and CL. APLN and APLNR protein levels were quantified in different ovarian cells from SF, MF and LF as described in 'Materials and methods' section. Vinculin (VCL) was used as a loading control. (A, B, C, D, E and F) For granulosa and theca cells for each group of follicle, a pool of 4 follicles per animal was used and 6 different animals were studied. For oocytes of each group of follicle, 6 pools each containing 10 (for mRNA, A, B and C) or 50 oocytes (for immunoblot, D, E and F) from various animals were studied. Statistical analyses were separately performed for each protein (APLN and APLNR). The results are expressed as the mean \pm S.E.M. Bars with different letters are significantly different $(P<0.05)$. 


\section{Effect of IGF1 and FSH on APLN and APLNR expression in bovine granulosa cells}

We next investigated the effect of IGF1 $\left(10^{-8} \mathrm{M}\right)$ and $\mathrm{FSH}\left(10^{-8} \mathrm{M}\right)$, two main hormones involved in the proliferation and differentiation of ovarian cells, on APLN and APLNR mRNA expression in primary bovine granulosa cells. Overnight-starved cells (with 1\% FBS) were incubated for $24 \mathrm{~h}$ with IGF1 $\left(10^{-8} \mathrm{M}\right)$ or FSH $\left(10^{-8} \mathrm{M}\right)$. Using real-time quantitative PCR, we showed that, after $24 \mathrm{~h}$ of stimulation, IGF1 increased APLN mRNA expression (Fig. 2A), whereas it decreased the mRNA expression of APLNR (Fig. 2B). Furthermore, we did not observe any significant effect of FSH on APLN or APLNR mRNA expression (Fig. 2A and B). For APLN expression, we confirmed these results at the protein level by immunoblot (Fig. 2C). As shown
A

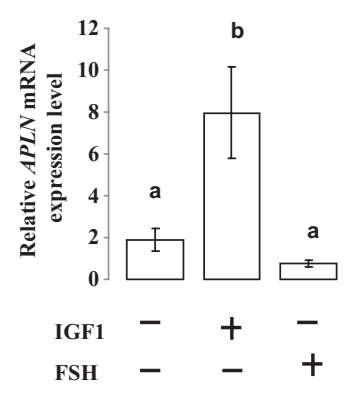

$\mathrm{C}$

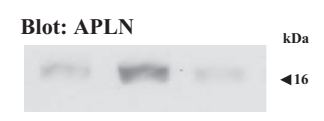

Blot: VCL

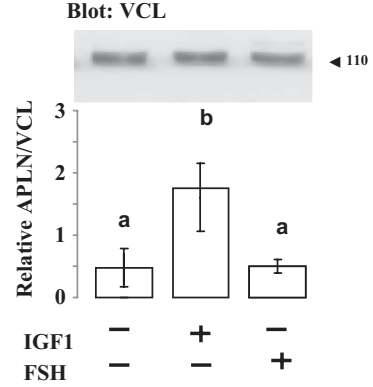

B

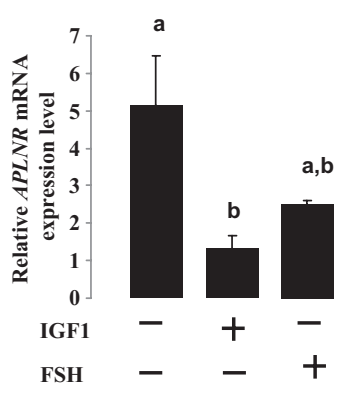

$\mathrm{D}$

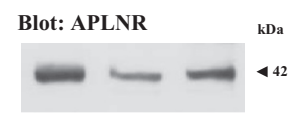

Blot: VCL

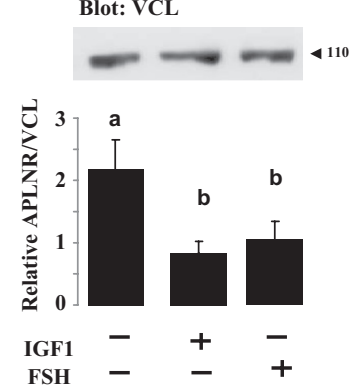

Figure 2 Effect of IGF1 and FSH on APLN and APLNR mRNA (A, B) and protein $(C, D)$ expression levels in primary bovine granulosa cells. (A, B) APLN and APLNR mRNA expression was measured by quantitative RT-PCR in primary bovine GCs after $24 \mathrm{~h}$ of stimulation with or without IGF1 $\left(10^{-8} \mathrm{M}\right)$ or FSH $\left(10^{-8} \mathrm{M}\right)$. The results represent four cultures of GCs and are presented as mean \pm S.E.M. Different letters indicate significant differences at $P<0.05$. (C, D) Granulosa cell lysates were also subjected to immunoblotting using antibodies raised against the APLN and APLNR protein. Equal protein loading was verified by reprobing membranes with an anti-VCL antibody. Blots were quantified and the APLN and APLNR to VCL ratio are shown. The results are expressed as the mean \pm S.E.M. of four independent cultures. Bars with different letters are significantly different $(P<0.05)$. in Fig. 2D, we showed that IGF1 but also FSH reduced the APLNR protein level. Similar results were observed when cells were incubated for $48 \mathrm{~h}$ with IGF1 or FSH (Supplementary Fig. 1A, B, C and D, see section on supplementary data given at the end of this article).

\section{Effects of APLN on progesterone secretion by bovine granulosa cells}

In order to determine the effect of APLN on the production of progesterone, primary bovine granulosa cells were incubated with various concentrations of APLN-17 or APLN-13 $\left(10^{-9}, 10^{-8}\right.$ and $\left.10^{-6} \mathrm{M}\right)$ for $48 \mathrm{~h}$ (Fig. $3 \mathrm{~A}$ and $\mathrm{C})$ or with APLN-17 $\left(10^{-9} \mathrm{M}\right)$ or APLN-13 $\left(10^{-9} \mathrm{M}\right)$ in the presence or absence of $\mathrm{FSH}\left(10^{-8} \mathrm{M}\right)$ or IGF1 $\left(10^{-8} \mathrm{M}\right)$ for $48 \mathrm{~h}$ (Fig. $3 \mathrm{~B}$ and D). Furthermore, to confirm a specific effect of APLN, we pre-incubated or not primary bovine granulosa cells with the APJ antagonist, ML221, in all the conditions described above. As shown in Fig. 3A and $\mathrm{C}$, the secretion of progesterone was increased by either $\mathrm{APLN}-13$ or APLN-17 treatment at a concentration of $10^{-9} \mathrm{M}$ or greater $(P<0.001)$. Two-way ANOVA indicates a significant effect of the concentration of APLN-17 (Fig. 3A) or APLN-13 (Fig. 3C) $(P<0.05)$, a significant effect of the ML221 treatment $(P<0.05)$, and no significant interaction between the concentration used and the ML221 treatment. In the presence of IGF1 $\left(10^{-8} \mathrm{M}\right)$ but not $\mathrm{FSH}\left(10^{-8} \mathrm{M}\right), \mathrm{APLN}-13$ or APLN$17\left(10^{-9} \mathrm{M}, 48 \mathrm{~h}\right)$ increased significantly progesterone release $(P<0.001)$ (Fig. 3B and D). As shown in Fig. 3A and $\mathrm{B}$, the $\mathrm{APLN}-17$ induced progesterone secretion in unstimulated cells (Fig. 3A) or in response to IGF1 (Fig. 3B) was abolished in the presence of ML221 $(10 \mu \mathrm{M})$. Similar results concerning the effect of APLN13 were obtained (Fig. 3C and D). Two-way ANOVA indicates a significant effect of the treatments (APLN17, APLN-13, IGF1 and FSH $(P<0.05))$, a significant effect of the ML221 treatment $(P<0.05)$, and no significant interaction between the various treatments used and the ML221 treatment.

We next investigated the effect of APLN-13 treatment $\left(10^{-9} \mathrm{M}\right)$ on the production of progesterone in response to various concentrations of IGF1 $\left(0,10^{-10}, 10^{-9}, 10^{-8}\right.$, $\left.10^{-7}, 10^{-6} \mathrm{M}\right)$ (Fig. 4A) and FSH $\left(0,10^{-10}, 10^{-9}, 10^{-8}\right.$, $10^{-7}, 10^{-6} \mathrm{M}$ ) (Fig. 4C) for $48 \mathrm{~h}$ and with IGF1 $10^{-8} \mathrm{M}$ or $\mathrm{FSH} 10^{-8} \mathrm{M}$ for various times of stimulation $(0,24,48$ and $72 \mathrm{~h}$ ) (Fig. 4B and D). As shown in Fig. 4A and C, APLN13 treatment $(48 \mathrm{~h})$ increased secretion of progesterone whatever the IGF1 concentration $(P<0.05)$ whereas it did not affect the FSH response. Two-way ANOVA indicates a significant effect of the IGF1 (Fig. 4A) and FSH (Fig. 4C) concentration $(P<0.05)$, a significant effect of the APLN-13 treatment only in response to IGF1 but not to $\mathrm{FSH}(P<0.05)$, and no significant interaction between the concentration used and the APLN-13 treatment for both FSH and IGF1 experiments (Fig. 4A 
A

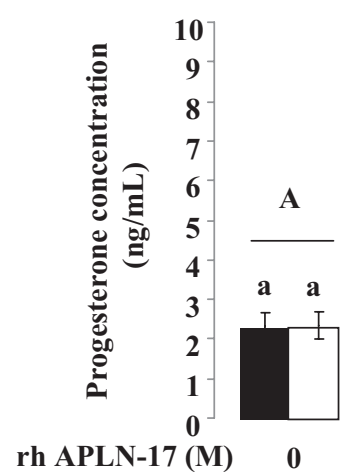

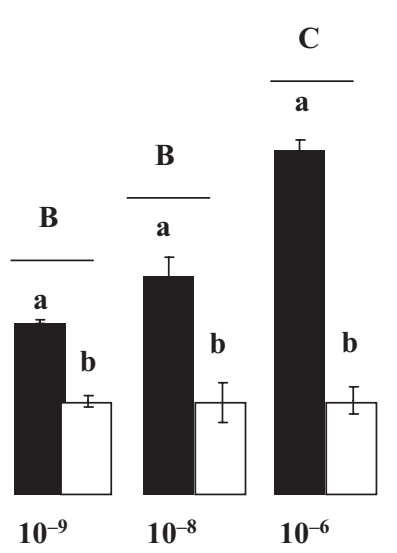

- Without ML221
C

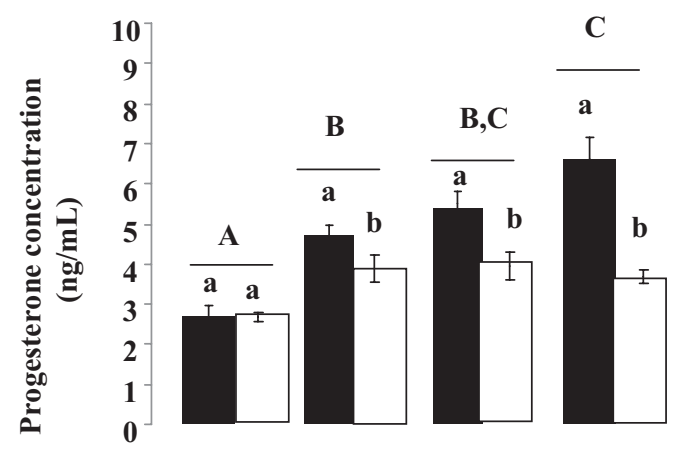

$\begin{array}{lllll}\text { rh APLN-13 (M) } & 0 & 10^{-9} & 10^{-8} & 10^{-6}\end{array}$
B

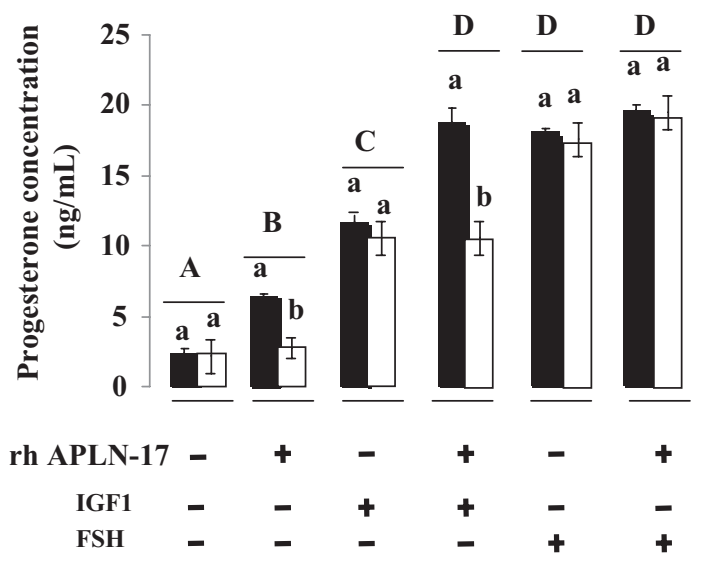

D

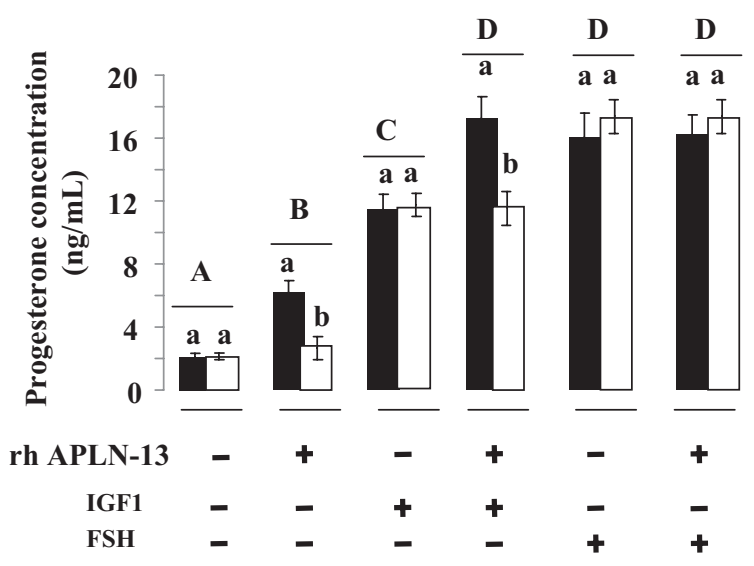

Figure 3 Effect of APLN-17 (A, B) and APLN-13 (C, D) on basal and FSH- or IGF1-stimulated secretion of progesterone by bovine granulosa cells. Granulosa cells from small bovine follicles were cultured for $24 \mathrm{~h}$ in medium with serum and then in serum-free medium in the presence or absence of various doses of APLN-17 (A) or APLN-13 (C) for $48 \mathrm{~h}$ or in the presence or absence of $10^{-9} \mathrm{M} \mathrm{APLN}-17$ or APLN-13 $\pm 10^{-8} \mathrm{M} \mathrm{FSH}$ or $\pm 10^{-8}$ M IGF1 (B and D) with or without the APJ antagonist, ML221 $(10 \mu \mathrm{M})$ as described in 'Materials and methods' section. The culture medium was then collected and analyzed for progesterone content by ELISA. Results are expressed as $\mathrm{ng} / \mathrm{mL}$ per well. Results are means \pm S.E.M. of three independent experiments. Bars with different letters are significantly different $(P<0.05)$. (A and C) Different capital letters indicate a significant effect of the APLN-17 (A) or APLN-13 (B) concentration, whereas lower case letters indicate a significant effect of the ML221 treatment. (B and D) Different capital letters indicate a significant effect of treatments (APLN-13 or -17, IGF1 or FSH), whereas lower case letters indicate a significant effect of the ML221 treatment.

and C). Also, APLN-13 treatment significantly $(P<0.05)$ increased progesterone production in the absence or in the presence of IGF1 for 24,48 and $72 \mathrm{~h}$, whereas it did not affect the FSH response whatever the time of stimulation (Fig. 4B and D). Two-way ANOVA indicates a significant effect of the duration of stimulation with IGF1 (Fig. 4B) and FSH (Fig. 4D), a significant effect of the APLN-13 treatment only in response to IGF1 but not to $\mathrm{FSH}$, and no significant interaction between the duration of stimulation and the APLN-13 treatment for both FSH and IGF1 experiments (Fig. 4B and D). Similar results were obtained with APLN-17 treatment (data not shown).

\section{Effects of APLN on granulosa cell proliferation}

We also examined the effect of APLN on the number of bovine GCs in culture, either by the induction of mitosis or by altering cell viability. Thymidine methyl$\left[{ }^{3} \mathrm{H}\right]$ incorporation by primary bovine GCs treated with different concentrations $\left(10^{-8}\right.$ and $\left.10^{-9} \mathrm{M}\right)$ of APLN-13 (Fig. 5A) or APLN-17 (Fig. 5B) or with APLN13 or APLN-17 $\left(10^{-9} \mathrm{M}\right)$ in the presence or absence of IGF1 $\left(10^{-8} \mathrm{M}\right)$ (Fig. 5C and D) was assessed after $24 \mathrm{~h}$ of culture. To confirm a specific effect of APLN, we pre-incubated or not primary bovine granulosa cells with the APJ antagonist, ML221 $(10 \mu \mathrm{M})$, in all 


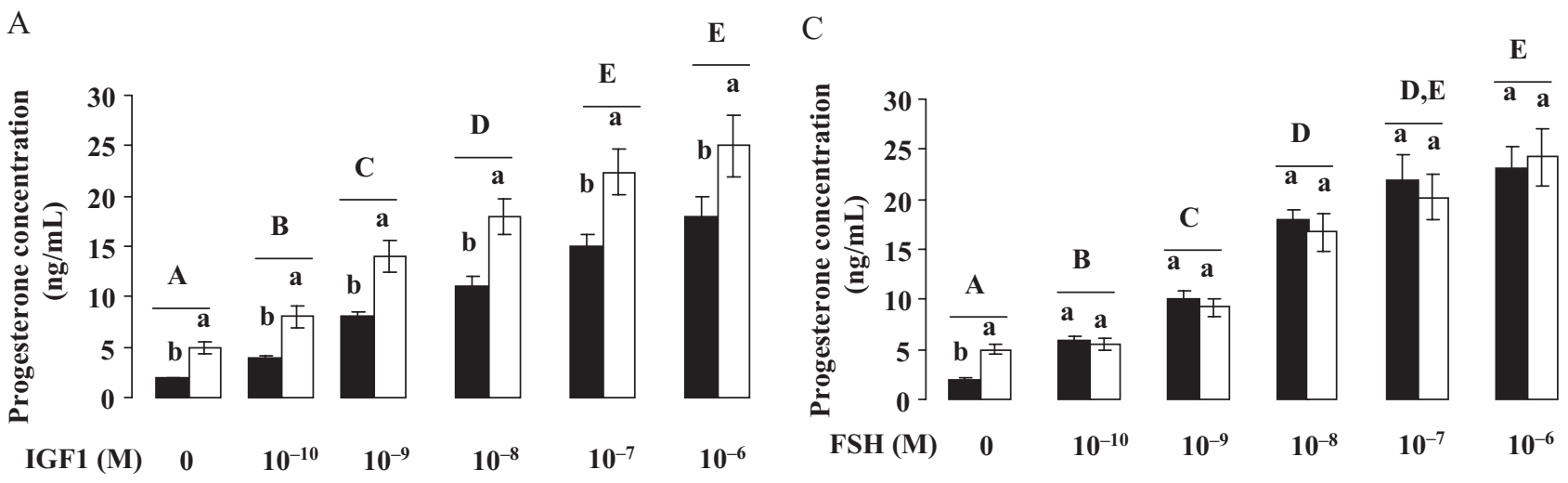

With rh APLN-13 (M) Without rh APLN-13 (M)

B

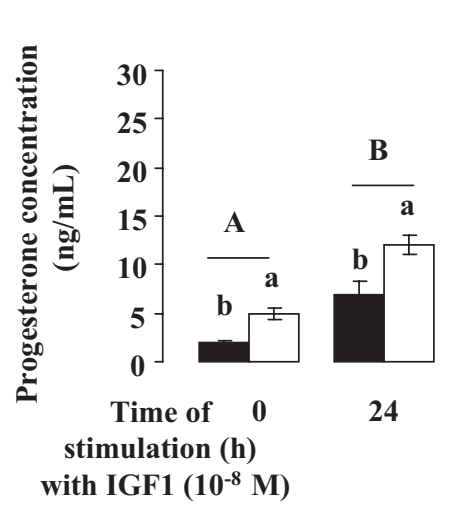

D

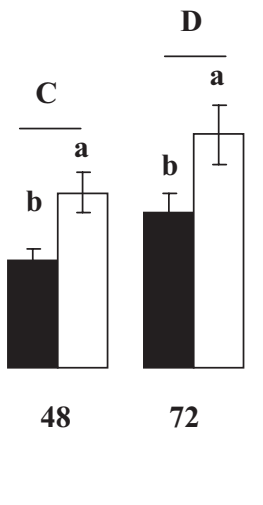

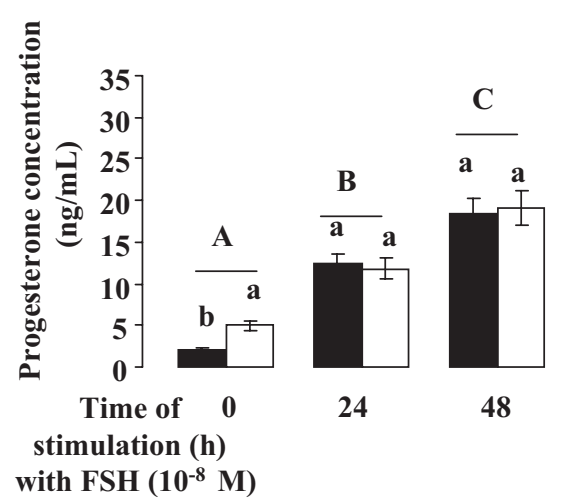

Figure 4 Effect of APLN-13 treatment on progesterone secretion by bovine granulosa cells in response to different doses and times of stimulation of IGF1 and FSH. Granulosa cells from small bovine follicles were cultured for $24 \mathrm{~h}$ in medium with serum and then in serum-free medium in the presence or absence of various doses of IGF1 (A) or FSH (C), for 48 h or for various times with IGF1 (10 $\left.{ }^{-8} \mathrm{M}\right)(\mathrm{B})$ or FSH (10 $\left.{ }^{-8} \mathrm{M}\right)(\mathrm{D})$ with or without APLN-13 treatment $\left(10^{-9} \mathrm{M}\right)$ as described in 'Materials and methods' section. The culture medium was then collected and analyzed for progesterone content. The results are expressed as protein concentration per well (ng/mL). The results are presented as mean \pm S.E.M. of three independent cultures. Bars with different letters are significantly different $(P<0.05)$. (A and C) Different capital letters indicate a significant effect of the IGF1 (A) or FSH (C) dose, whereas lower case letters indicate a significant effect of the APLN-13 treatment. (B and D) Different capital letters indicate a significant effect of the time of stimulation with IGF1 (B) or FSH (D), whereas lower case letters indicate a significant effect of the APLN-13 treatment.

the conditions described above. Two-way ANOVA indicates a significant effect of the concentration of APLN-17 (Fig. 5A) or APLN-13 (Fig. 5B) $(P<0.05)$, a significant effect of the ML221 treatment $(P<0.05)$, and no significant interaction between the concentration used and the ML221 treatment. As expected, IGF1 treatment significantly increased thymidine methyl- $\left[{ }^{3} \mathrm{H}\right]$ incorporation (Fig. 5C and D). In the basal state, cell proliferation was increased by APLN-13 and APLN-17 treatment (Fig. 5A and B). Furthermore, APLN-13 and APLN-17 also improved thymidine incorporation in response to IGF1 (Fig. 5C and D). All these results were abolished in the presence of ML221 (Fig. 5). Two-way ANOVA indicates a significant effect of the treatments (APLN-17 or APLN-13, IGF1, $(P<0.05)$ ), a significant effect of the ML221 treatment $(P<0.05)$, and no significant interaction between the various treatments used and the ML221 treatment. As revealed by staining with trypan blue, neither APLN-13 nor APLN-17 had an effect on cell viability in the absence or presence of IGF1 (data not shown). Thus, in the basal state, APLN13 or -17 increased both progesterone production and cell proliferation in the absence or in the presence of IGF1. All these data were obtained without affecting cell viability.

\section{Effects of APLN on cell signaling in bovine granulosa cells}

It is well known that APLN can activate various signaling pathways in different cell types (Bai et al. 2008, Liu et al. 2015, Yang et al. 2016). Here, we measured the effect 
A

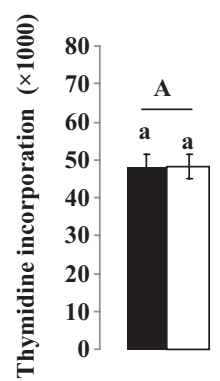

rh APLN-17 (M) 0



$10^{-9}$
$10^{-8}$
$\mathrm{B}$

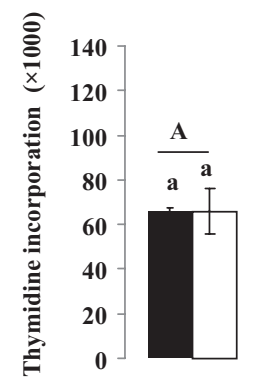

rh APLN-13 (M) 0

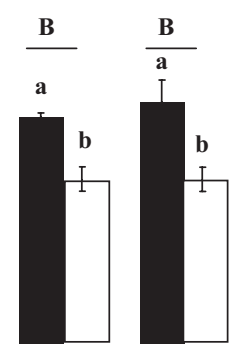

$10^{-9}$
$10^{-8}$

—Without ML221 $\square$ With ML221
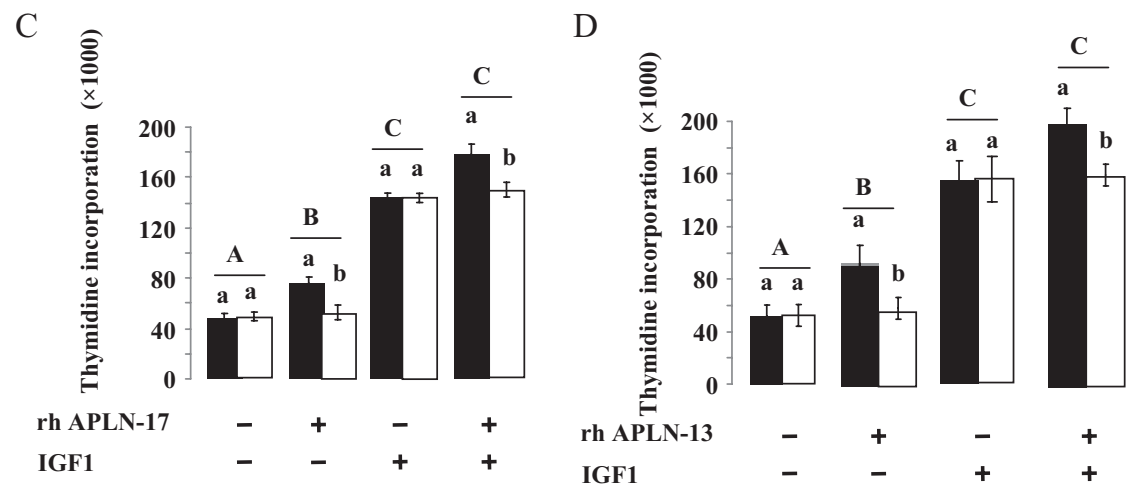

Figure 5 Effect of APLN-17 and APLN-13 on cell proliferation in the absence or presence of IGF1 in bovine granulosa cells. Thymidine incorporation was determined in bovine GCs cultured for $24 \mathrm{~h}$ in serum-free medium in the presence or absence of APLN-17 (A, C) and APLN-13 (B, D) in basal state $(A, B)$ or in response to IGFI $\left(10^{-8} \mathrm{M}\right)(\mathrm{C}, \mathrm{D})$ with or without ML221 as described in 'Materials and methods' section. Results are expressed as thymidine incorporated in cpm. Results are representative of at least three independent experiments. The results are expressed as means \pm S.E.M. Bars with different letters are significantly different $(P<0.05)$. (A and $\mathrm{B})$ Different capital letters indicate a significant effect of the concentration of APLN-17 (A) or APLN-13 (B) treatment, whereas lower case letters indicate a significant effect of the ML221 treatment. (B and D) Different capital letters indicate a significant effect of the treatment (APLN-17 (C), APLN-13 (D) or IGF1 (C and D), whereas lower case letters indicate a significant effect of the ML221 treatment. of APLN-13 $\left(10^{-9} \mathrm{M}\right)$ on the phosphorylation levels of mitogen-activated protein kinase (MAPK) ERK1/2 and p38, Akt and PRKA (Fig. 6A, B, C and D). As shown in Fig. 6A, B and $\mathrm{C}, \mathrm{APLN}-13$ rapidly activated (at 1 or $5 \mathrm{~min}, P<0.05$ ) the MAPK ERK1/2, p38 and Akt signaling pathways. However this activation was transient. On the contrary, PRKA phosphorylation was significantly decreased after 5 min of APLN-13 stimulation (Fig. 6D). Similar results were observed with APLN-17 (data not shown). Thus, APLN activates MAPK (ERK1/2 and p38) and Akt signaling and inhibits PRKA kinase in primary bovine GCs.

\section{Involvement of MAPK ERK1/2 in APLN-mediated effects on IGF1-induced progesterone secretion}

We next investigated the molecular mechanisms involved in the effect of APLN on progesterone production in the absence and in the presence of IGFI in primary bovine GCs. Cells were incubated in serumfree media supplemented with APLN-13 $\left(10^{-9} \mathrm{M}\right)$ for $48 \mathrm{~h}$, which were the same conditions used to measure progesterone production, either in the presence or in the absence of IGF1 $\left(10^{-8} \mathrm{M}\right)$ treatment for $5 \mathrm{~min}$ for the kinase phosphorylation studies (Fig. 7). As expected, treatment with IGF1 alone increased the phosphorylation of AKT (Fig. 7A) and MAPK ERK1/2 (Fig. 7B), whereas no effect was observed for MAPK P38 (Fig. 7C) and PRKA (Fig. 7D) phosphorylation. Treatment with only APLN-13 also increased the basal phosphorylation of
AKT, MAPK ERK1/2 and MAPK P38 and reduced that of PRKA. Furthermore, an additive effect of APLN13 and IGF1 was observed for MAPK ERK1/2 and AKT phosphorylation, but no effect was observed for MAPK P38 and PRKA phosphorylation when the two hormones were combined (Fig. 7A, B, C and D). To demonstrate the involvement of the MAPK ERK $1 / 2$ and AKT signaling pathways in the observed effect of APLN-13 on progesterone secretion in the absence or in the presence of IGF1, we used two pharmacological

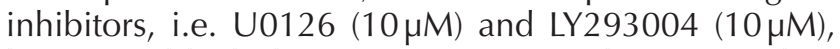
known to block the MAPK ERK1/2 and AKT signaling pathways respectively. As shown in Fig. 7E, U0126 but not LY293004 significantly reduced progesterone production in response to APLN-13 in the presence or absence of IGF1. Thus, these data suggest that MAPK ERK1/2 but not AKT is involved in APLN-13-induced progesterone synthesis in response to IGF1.

\section{Involvement of the AKT signaling pathway in APLN- mediated effects on IGF1-induced cell proliferation}

We then determined the molecular mechanisms involved in the observed effect of APLN-13 on cell proliferation in response to IGF1 in primary bovine granulosa cells. The cells were pre-incubated in serumfree media with U0126 $(10 \mu \mathrm{M})$, LY293004 $(10 \mu \mathrm{M})$, SB202190 $(10 \mu \mathrm{M})$ and Compound $\mathrm{C}(10 \mu \mathrm{M})$, known to block the MAPK ERK1/2, AKT, MAPK P38 and PRKA 
A


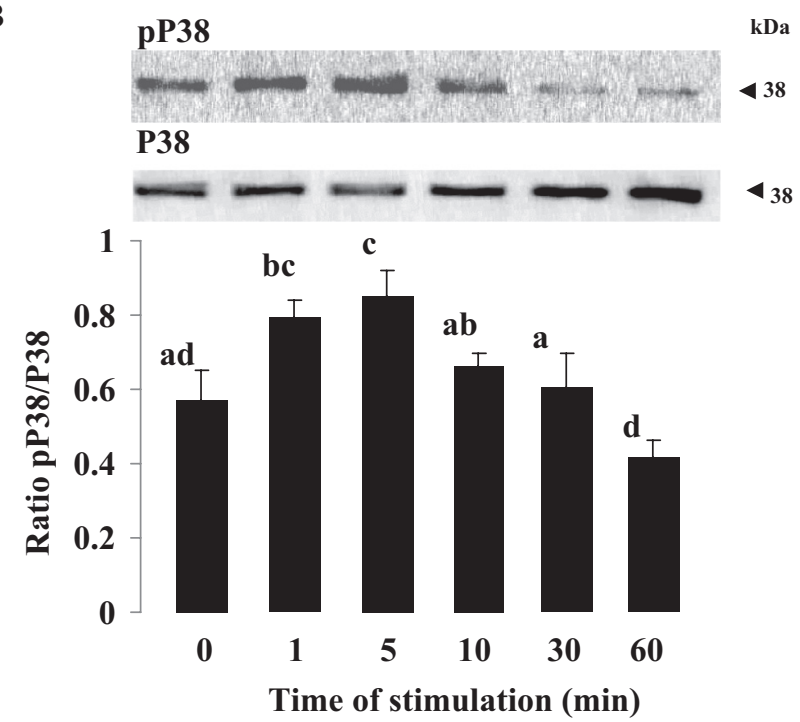

$\mathrm{D}$

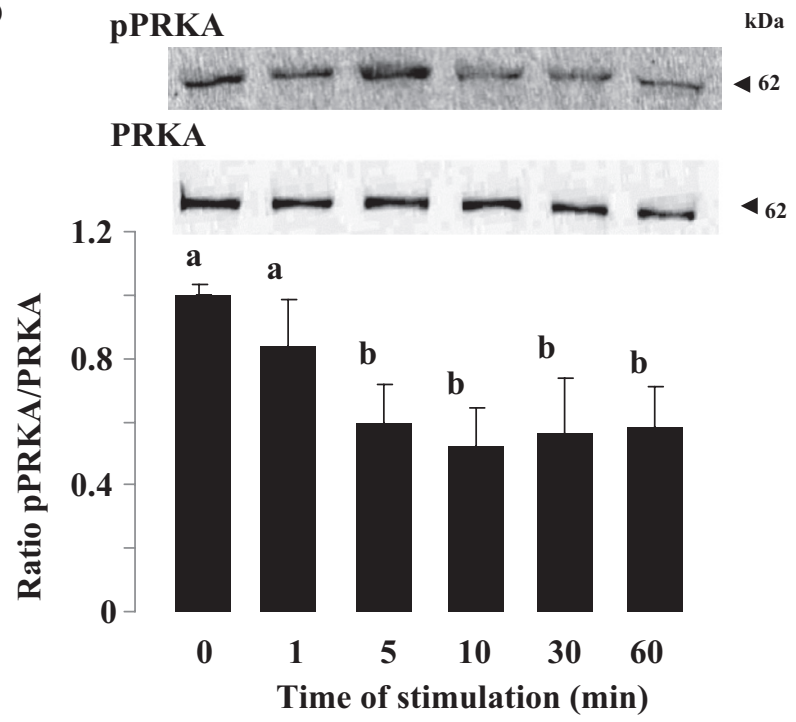

Figure 6 Effect of APLN-13 $\left(10^{-9} \mathrm{M}\right)$ on (A) MAPK ERK1/2, (B) MAPK P38, (C) AKT and (D) PRKA phosphorylation levels. Bovine GC lysates were prepared from cells incubated with APLN-13 $\left(10^{-9} \mathrm{M}\right)$ for either $0,1,5,10,30$ or $60 \mathrm{~min}$. Lysates $(50 \mu \mathrm{g})$ were analyzed by immunoblotting using either (A) anti-phospho-MAPK ERK1/2, (B) phospho-MAPK P38, (C) phospho-AKT or (D) phospho-PRKA antibodies, and then with anti-MAPK ERK2, AKT MAPK P38 and PRKA total protein antibodies. Representative blots from three independent experiments are shown. Blots were quantified and the phospho-protein to total protein ratios are shown. The results are presented as mean \pm S.E.M. Different letters indicate significant differences $(P<0.05)$.

signaling pathways respectively and then stimulated the cells or not with IGF1 $\left(10^{-8} \mathrm{M}\right)$ for $24 \mathrm{~h}$. As shown in Fig. 8, only LY293004 $(10 \mu \mathrm{M})$ significantly reduced APLN-13-induced thymidine incorporation in the basal state and in response to IGF1. Thus, these data suggest that the AKT signaling pathway is involved in APLN-13induced cell proliferation in response to IGF1.

\section{Effects of APLN on in vitro bovine oocyte maturation}

We also studied the effects of APLN-13 and APLN17 on the meiotic progression of bovine oocytes in cumulus-oocyte complexes (COCs) during in vitro maturation (IVM) in the absence or presence of IGF1 $\left(10^{-8} \mathrm{M}\right)$ or $\mathrm{FSH}\left(10^{-8} \mathrm{M}\right)$. For the control group, after $22 \mathrm{~h}$ of culture in IVM medium, most oocytes underwent germinal vesicle breakdown (GVBD) in the absence or in the presence of IGF1 $\left(10^{-8} \mathrm{M}\right)$ or FSH $\left(10^{-8} \mathrm{M}\right)$; about $95 \%$ of oocytes had progressed to the metaphase II stage, with less than $10 \%$ remaining at the GV stage (Fig. 9A). Conversely, if COCs matured in the presence of APLN-13 $\left(10^{-9} \mathrm{M}\right)$, meiotic progression was inhibited except if $\mathrm{FSH}\left(10^{-8} \mathrm{M}\right)$ was present in 


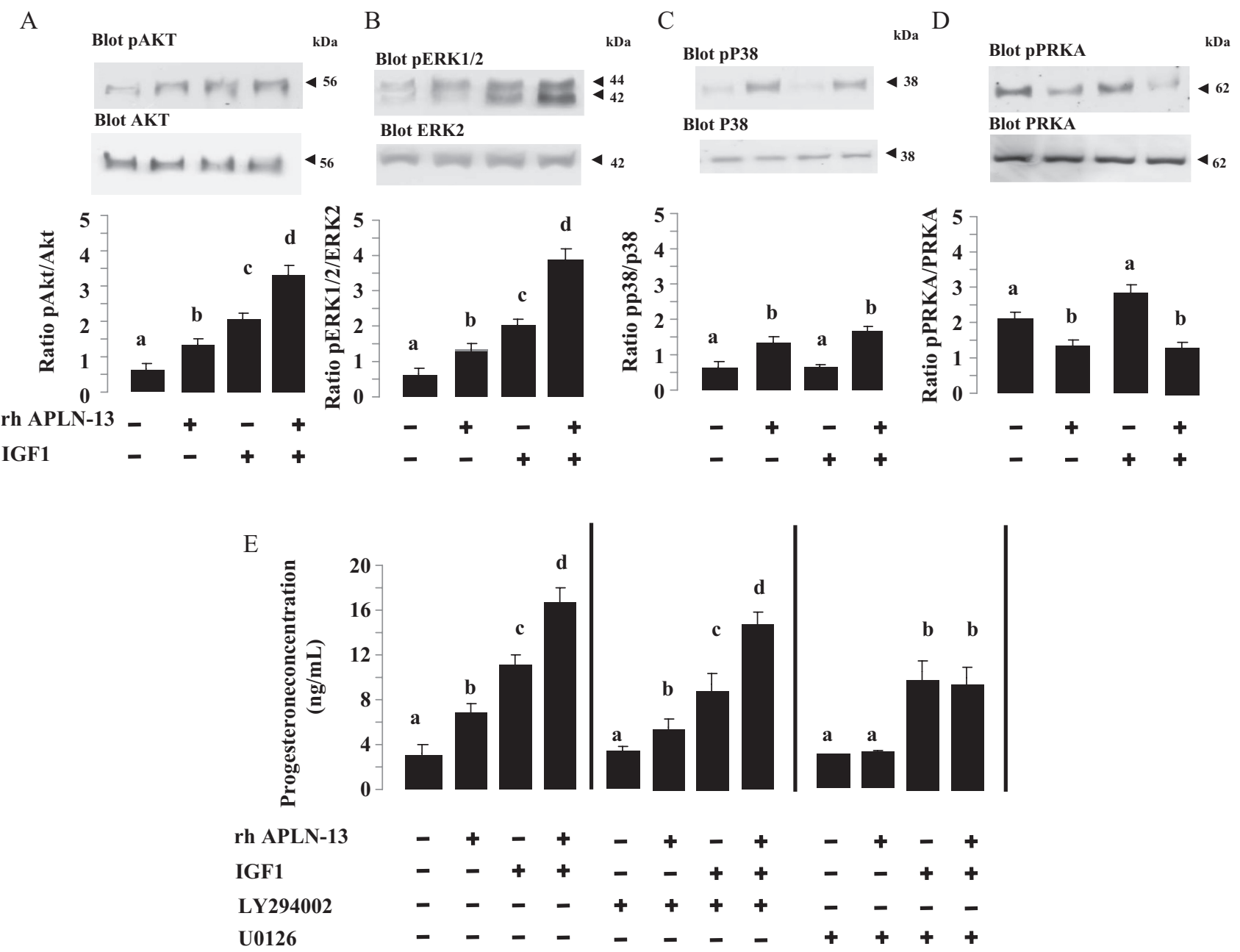

Figure 7 Effect of APLN-13 (10-9 M) on the phosphorylation of (A) AKT, (B) MAPK ERK1/2, (C) MAPK P38 and (D) PRKA in response to IGF1 in primary bovine granulosa cells. (A, B, C and D) Primary bovine granulosa cells were cultured in a media containing serum and then cultured in serum-free media for $48 \mathrm{~h}$ in the presence or absence of APLN-13 $\left(10^{-9} \mathrm{M}\right)$, which were the same conditions used to measure progesterone production and then stimulated with IGF1 $\left(10^{-8} \mathrm{M}\right)$ for $5 \mathrm{~min}$. Cells were lysed and the lysates were directly subjected to immunoblotting with antibodies against (A) phospho-AKT, (B) phospho-MAPK ERK1/2, (C) phospho-MAPK P38 or (D) anti-phospho-PRKA. The AKT, MAPK ERK1/2, MAPK P38 and PRKA levels were evaluated by reprobing the membranes with antibodies for total AKT, ERK2, MAPK P38 and PRKA, respectively. Representative blots from four different cultures are shown. Blots were quantified and the phosphorylated protein to total protein ratio is shown. The results are represented as mean \pm S.E.M. (E) Involvement of the MAPK ERK1/2 signaling pathways in the effect of APLN-13 on the progesterone secretion in the presence or absence of IGF1. Overnight starved hGCs were preincubated for one hour with either U0126 $(10 \mu \mathrm{M})$ or LY293004 $(10 \mu \mathrm{M})$ and then cultured for $48 \mathrm{~h}$ in serum-free media containing APLN-13 $\left(10^{-9} \mathrm{M}\right)$ in the absence or presence of IGFI $\left(10^{-8} \mathrm{M}\right)$. (A) The culture medium was then collected and analyzed for progesterone content. The results are expressed as protein concentration per well $(\mathrm{ng} / \mathrm{mL})$. The results are presented as the mean \pm S.E.M. of three independent cultures. Bars with different letters are significantly different $(P<0.05)$.

the IVM medium (Fig. 9A). Indeed, in COCs matured for $22 \mathrm{~h}$ in IVM medium supplemented with APLN-13 $\left(10^{-9} \mathrm{M}\right)$ in the absence or presence of IGF1 $\left(10^{-8} \mathrm{M}\right)$, about $65 \%$ of oocytes remained at the GV stage (Fig. 9A). Similar results were observed with APLN$17\left(10^{-9} \mathrm{M}\right.$, Fig. 9C). Thus, APLN treatment of COCs during IVM resulted in meiotic arrest in the absence or presence of IGF1. Progesterone secretion by cumulus cells is known to play a key role in bovine oocyte maturation (Zhang \& Armstrong 1989, Borman et al. 2004). We therefore investigated the effects of APLN treatment (APLN-13 (Fig. 9B) and APLN-17 (Fig. 9D)) on progesterone secretion by COCs. The addition of APLN-13 or APLN-17 to the maturation medium for $22 \mathrm{~h}$ significantly decreased progesterone secretion in COCs in the absence or presence of IGF1 but not in the presence of FSH (Fig. 9B).

We investigated the molecular mechanisms involved in the effects of APLN on the nuclear maturation of bovine oocytes in COCs by determining the levels of MAPK ERK1/2 and PRKA phosphorylation in the presence or absence of APLN-13 $\left(10^{-9} \mathrm{M}\right)$ in COCs 


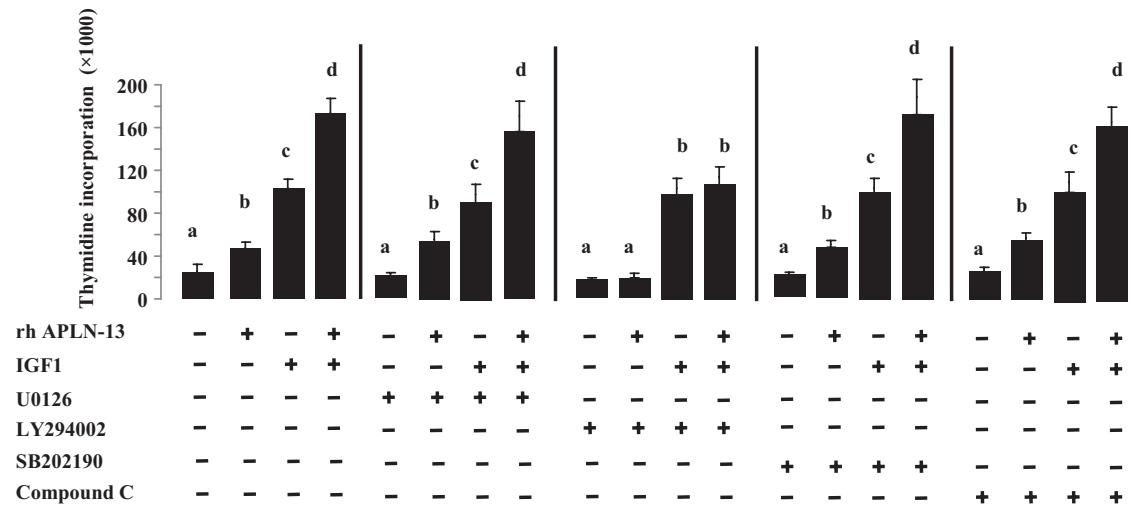

Figure 8 Involvement of the AKT signaling pathways in the effect of APLN-13 on the thymidine incorporation level in the presence or absence of IGF1. Thymidine incorporation was determined in overnight-starved bovine granulosa cells preincubated for one hour with either U0126 $(10 \mu \mathrm{M})$, LY293004 $(10 \mu \mathrm{M})$, SB202190 $(10 \mu \mathrm{M})$, or Compound C $(10 \mu \mathrm{M})$ and then stimulated for $24 \mathrm{~h}$ in serum-free media containing APLN-13 $\left(10^{-9} \mathrm{M}\right)$ in the absence or presence of IGFI $\left(10^{-8} \mathrm{M}\right)$. Results are expressed as thymidine incorporated in $\mathrm{cpm}$. Results are representative of at least three independent experiments. The results are expressed as means \pm S.E.M. allowed to mature in vitro for $22 \mathrm{~h}$. MAPK ERK1/2 and PRKA are two crucial signaling pathways involved in the bovine oocyte maturation (Tosca et al. 2007a,b). As expected and as shown in Fig. 10A and B, the level of MAPK ERK1/2 phosphorylation increased and those of PRKA decreased in the oocytes from COCs during IVM in the absence or in the presence of IGF1 or FSH (Tosca et al 2007a,b). The addition of APLN-13 $\left(10^{-9} \mathrm{M}\right)$ in the absence or in the presence of IGF1 to the maturation medium for $22 \mathrm{~h}$ significantly decreased MAPK ERK1/2 phosphorylation, whereas it increased PRKA phosphorylation in oocytes from COCs. However the APLN-13 treatment did not affect the FSH effect on MAPK ERK1/2 and PRKA phosphorylation. Similar results were observed in response to APLN-17 treatment (data not shown). Thus, APLN treatment during IVM decreased MAPK ERK1/2 and increased PRKA phosphorylation in the absence or presence of IGF1 in oocytes from COCs.

\section{Discussion}

In the present study, we identified APLN and APLNR in bovine ovarian cells from different sizes of follicle. In cultured granulosa cells, we observed that their expression was differently regulated by IGF1, an important hormone involved in the differentiation of ovarian follicles. We also showed that APLN (isoforms 13 and 17) increased progesterone production and cell proliferation through the MAPK ERK $1 / 2$ and AKT signaling pathways respectively. Conversely, we demonstrated that APLN-13 and APLN-17 in basal state or in response to IGF1 decrease in vitro oocyte maturation, which was associated with a decrease in progesterone production by COCs in IVM medium, a reduction in MAPK ERK1/2 phosphorylation and an increase in PRKA phosphorylation in oocytes.

APLN-APLNR has been described in many organs including the brain, uterus and ovary $\left(\mathrm{O}^{\prime}\right.$ Carroll et al. 2013), suggesting a role in reproductive functions. In
A

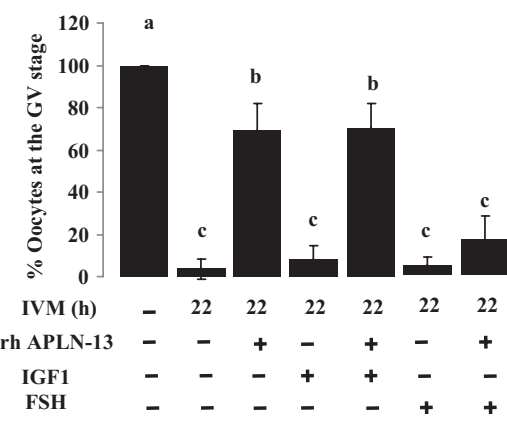

B

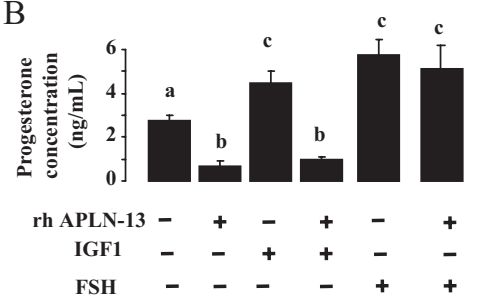

C

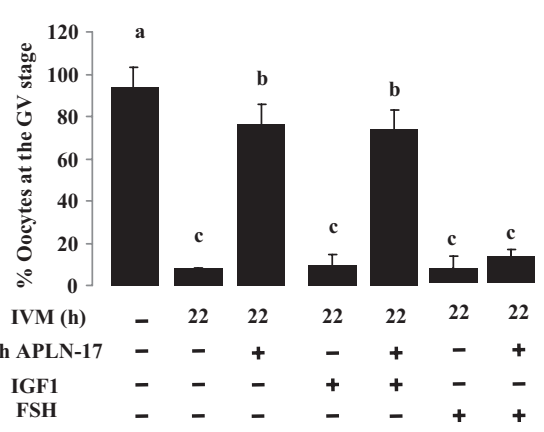

D

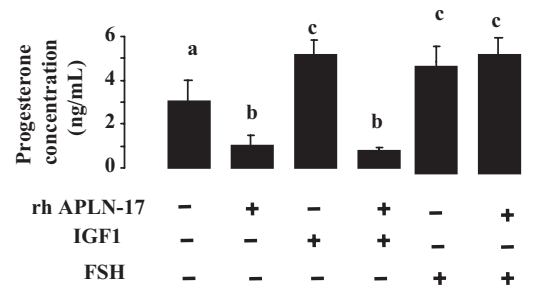

Figure 9 Effects of APLN-13 (A and B) and APLN-17 (C and D) on bovine oocyte nuclear maturation. (A) Bovine oocytes were allowed to mature for $22 \mathrm{~h}$ in the presence or absence of APLN-13 $\left(10^{-9} \mathrm{M}\right)(\mathrm{A})$ or APLN-17 $\left(10^{-9} \mathrm{M}\right)$ (C) with or without IGF1 $\left(10^{-8} \mathrm{M}\right)$ or FSH $\left(10^{-8} \mathrm{M}\right)$. The percentage of oocytes at the GV stage in the various conditions is shown.

Different letters indicate significant differences with $P<0.05$. The results are presented as mean \pm S.E.M. of three independent experiments. At least 50 bovine oocytes for each set of conditions in each experiment were used. (B) Bovine COCs were cultured for $22 \mathrm{~h}$ in maturation medium in the presence or absence of APLN-13 (B) or APLN-17 (D) \pm IGF1 $\left(10^{-8} \mathrm{M}\right)$ or FSH $\left(10^{-8} \mathrm{M}\right)$. The culture medium was then collected, and its progesterone content was analyzed by ELISA as described in 'Materials and methods' section. The results are expressed as $\mathrm{ng} / \mathrm{mL}$ of 50 COC-equivalent cumulus cells. The results are mean \pm S.E.M. for three independent experiments. Different letters indicate significant differences with $P<0.05$. 
A

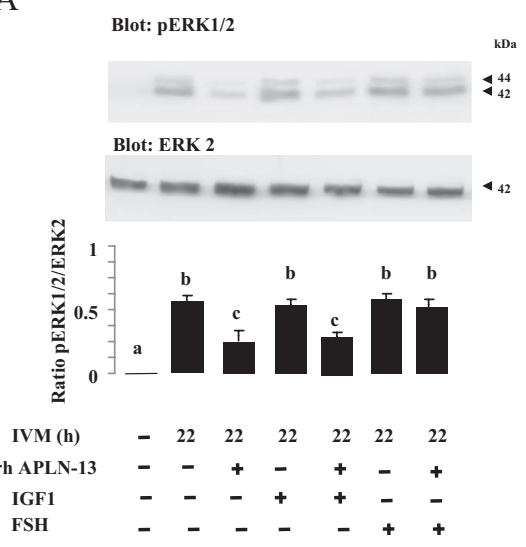

B

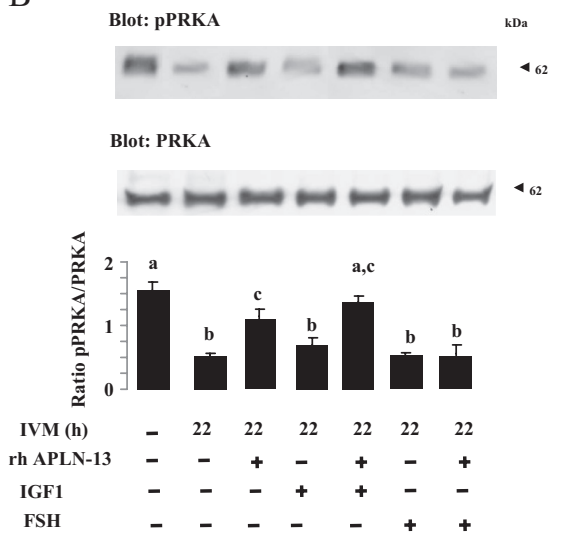

Figure 10 Effect of APLN-13 in the absence or presence of IGF1 or FSH on MAPK ERK1/2 (A) and PRKA (B) phosphorylation levels in bovine oocyte after nuclear maturation bovine COCs were cultured for $22 \mathrm{~h}$ in maturation medium in the presence or absence of APLN-13 \pm IGF1 $\left(10^{-8} \mathrm{M}\right)$ or FSH $\left(10^{-8} \mathrm{M}\right)$. COCs were then mechanically separated into oocyte and cumulus cells. Denuded oocytes (50 oocytes per lane) were lysed and subjected to Western blot analysis with antibodies against phospho-MAPK ERK1/2 (A) and phospho-PRKA (B). Representative blots from three independent experiments are shown. Blots were quantified, and the phosphorylated protein to total protein ratio is shown. Different letters indicate significant differences with $P<0.05$. The results are presented as mean \pm S.E.M. the bovine ovary, they are found in follicles during final growth up to the preovulatory stage (Schilffarth et al. 2009). In the present study, we showed that APLN and APLNR are expressed not only in granulosa and theca interstitial cells, as already observed (Schilffarth et al. 2009, Shimizu et al. 2009), but also in oocytes. Furthermore, we demonstrated that APLN and APLNR expression in granulosa and oocytes significantly increased with ovarian follicles size whereas it was unchanged in theca interstitial cells. Other adipokines such as NAMPT (Reverchon et al. 2016), RARRES2 (Reverchon et al. 2014) and ADIPOQ (Maillard et al. 2010) have been reported in bovine cumulus-oocyte complexes. However the role of APLN-APLNR in the oocyte remains to be determined. In cultured granulosa from small follicles, we demonstrated that IGF1 but not FSH increases APLN expression, whereas it decreases the expression of APLNR. IGF1 is an intraovarian growth factor that plays a key role in the control of follicular development in mammals (Silva et al. 2009). More precisely, IGF1 is known to stimulate granulosa cell proliferation and progesterone production (Reverchon et al. 2016). In bovine granulosa cells, an increase in the expression of APLNR mRNA is associated with follicular atresia (Shimizu et al. 2009). Thus, the negative effect of IGF1 on APLNR mRNA expression could explain the positive effect of IGF1 on cell survival. Another study has also shown that progesterone stimulates the expression of APLNR in granulosa cells (Shimizu et al. 2009). Thus, APLNR can be regulated by different metabolic and reproductive hormones. In PCOS patients, in our laboratory, we observed that follicular fluid APLN-13 levels and granulosa APLN and APLNR mRNA expression were higher than those observed in control patients (Roche et al. 2016). In humans, the link between serum APLN and PCOS is unclear. Indeed, some studies have described higher serum APLN levels in PCOS patients (Cekmez et al. 2011, Goren et al. 2012, Sun et al. 2015), whereas others have reported an inverse association (Altinkaya et al. 2014, Chang et al. 2011). Moreover, according to these studies, a significant correlation between serum APLN and glucose and insulin is not always observed, suggesting that APLN cannot be used as a marker of insulin sensitivity. These contradictory data can be explained by some differences in ethnicity, age, study design and sample size.

In the present study, we showed that the APLN-13 and APLN-17 isoforms increased basal and IGF1induced progesterone secretion by cultured bovine granulosa cells. This effect was abolished when cells were pre-incubated with the APLNR antagonist ML221, suggesting a specific effect of APLN. Furthermore, using different pharmacological inhibitors, we observed that these effects were mediated through the MAPK ERK $1 / 2$ signaling pathways. In male rats, it has been reported that that an intracerebroventricular infusion of high-dose APLN-13 decreases testosterone release by suppressing luteinizing hormone secretion (Sandal et al. 2015). In that study, the number of Leydig cells decreased; however no direct effect of APLN on steroidogenesis has been described in this species. In bovine species, no studies have yet investigated the effect of APLN on gonadotropin secretion. However all these data suggest that APLN may affect reproductive functions at different levels of the hypothalamopituitary-gonadal axis. In bovine species, several adipokines have already been described to regulate steroid secretion by granulosa cells in the basal state or in response to IGF1 or insulin. For example, ADIPOQ (Maillard et al. 2010) as well as RARRES2 (Reverchon et al. 2014) decrease insulin/IGF1-induced granulosa cell steroidogenesis, whereas NAMPT increases it (Reverchon et al. 2016). In the present study, we showed that the positive effect of APLN on progesterone secretion on bovine granulosa cells was mediated by the activation of MAPK ERK $1 / 2$. This latter signaling pathway is well known to be involved in the regulation of the ovarian steroidogenesis in different 
species, including rat (Tosca et al. 2005) and cow (Tosca et al. 2007a).

We demonstrated for the first time that APLN and its receptor are expressed in bovine ovarian cells. However it remains to show that APLN produced by these cells is released and active. Indeed, while we showed in primary granulosa cells that the expression levels of APLN were increased by addition of IGF1, the APLNR antagonist ML221 did not show any significant effect on progesterone production or cell proliferation unless cells were stimulated with recombinant human APLN. We tried to measure the APLN concentration in the conditioned culture medium by ELISA. However the levels were undetectable suggesting that although ovarian cells may express APLNR and may be capable of responding to exogenous APLN protein, endogenous levels of APLN protein production may not be sufficient to regulate the cell functions. Thus, one hypothesis is that the APLN effects on the ovarian cells would be more systemic than local. However it remains to be demonstrated by developing mice lacking APLN specifically in oocyte or granulosa cells.

We observed that APLN (the 13 and 17 isoforms) increased cell proliferation in the basal state and in response to IGF1 through the PI3K/AKT signaling pathway, whereas APLN did not affect apoptosis in bovine granulosa cells. Our results are in good agreement with the recently described findings in rat (Shuang et al. 2016) showing that APLN promotes granulosa cell proliferation. Other studies have also shown a positive effect of APLN-13 on cell growth in the breast cancer cell line MCF-7 (Peng et al. 2015) and the lung adenocarcinoma cell line A549 (Yang et al. 2014). In the present study, we did not observe any effect of APLN (13 or 17) on apoptosis in granulosa cells. These data contrast those previously described in bovine granulosa cells (Shimizu et al. 2009). However, in that study, the authors did not incubate bovine granulosa cells with APLN, but rather associated the two events (apoptosis and variations in APJ expression). APLN is well known to exert insulin-mimetic effects and consequently regulate energy metabolism and insulin sensitivity (Dray et al. 2008, Yue et al. 2010). Since IGF1 and IGF1R have a similar structure to those of insulin and the insulin receptor (Dupont et al. 2003), APLN may increase IGF1 sensitivity in granulosa cells as already described in muscle in mice (Dray et al. 2008) and consequently improve not only steroidogenesis but also proliferation.

For the first time, we have shown the presence of APLN and APLNR in the bovine oocyte. Furthermore, we observed that APLN-13 and APLN-17 decreased in vitro oocyte maturation and this was associated with a reduction in progesterone levels in IVM medium and variations in MAPK ERK $1 / 2$ and PRKA phosphorylation levels in oocytes. APLN may block bovine nuclear oocyte maturation through the inhibition of progesterone secretion by COCs. Indeed, various studies have reported that progesterone is crucial for oocyte maturation (Zhang \& Armstrong 1989, Borman et al. 2004). Furthermore, the strong reduction in APLN-induced MAPK ERK1/2 phosphorylation observed in bovine oocytes could also contribute to explaining the inhibitory effect of APLN on oocyte maturation. Indeed, an increase in MAPK ERK1/2 phosphorylation in oocytes at the beginning of maturation has been described in different species, including bovine species (Fissore et al. 1996). Furthermore, in parallel with the inhibition in APLNinduced MAPK ERK1/2, we observed an increase in PRKA phosphorylation in oocytes that could contribute to explain the blockage of APLN in oocyte maturation. Several data showed that pharmacological activation of PRKA blocks nuclear oocyte maturation in cattle (Bilodeau-Goeseels et al. 2007, Tosca et al. 2007b). In our study, we observed that APLN-13 increased basal and IGF1-induced progesterone production in cultured granulosa cells, whereas it reduced progesterone production by COCs in in vitro maturation medium. In COCs, progesterone is produced by cumulus cells, which are also granulosa cells. However some studies have shown that mural granulosa cells and cumulus cells have differences in their gonadotropin receptor content and in progestin secretion responsiveness to gonadotropins (Magnusson et al. 1982). Furthermore, it will be interesting to compare the expression and the molecular mechanism of APLN/APLNR in mural granulosa and cumulus cells. The culture conditions (medium, attached cells for mural granulosa cells, and cell suspension for COCs) could also explain the contradictory data regarding the effect of APLN on mural granulosa cells and cumulus cells. Indeed, the contrasting data on progesterone production and MAPK ERK1/2 phosphorylation between mural granulosa cells and cumulus cells could be related to the $10 \%$ bovine fetal serum in the culture medium used for the seeding of mural granulosa cells in order to improve the cell attachment. Indeed, it is well known that the use of serum induces luteinization of cells thus not representing the physiology of a healthy growing follicle (Gutiérrez et al. 1997).

In conclusion, APLN and its receptor are present in bovine ovarian cells including granulosa cells and oocytes. We showed that APLN can increase progesterone secretion from luteinizing granulosa cells, whereas it inhibits oocyte maturation and progesterone secretion from cumulus cells in vitro. In the face of the lack of influence of APLN blockers alone on the parameters assessed herein and limitations of the in vitro culture system, further studies are necessary to confirm a physiological role for APLN in the control of folliculogenesis. 


\section{Supplementary data}

This is linked to the online version of the paper at http://dx.doi. org/10.1530/REP-16-0677.

\section{Declaration of interest}

No conflict of interest. Maxime Reverchon and Namya Mellouk are PhD students supported by a grant from the MENRT.

\section{Funding}

This work was financially supported by region center 'Adipofertikines proposal' Grant Number: 32000407, Institut National de la Recherche Agronomique and by Campus France for the PHC project under the bilateral Polish-France Agreement 'POLONIUM' (2016-2017).

\section{Acknowledgements}

We would like to thank Thierry Delpuech, Jean-Noel Couet, and Gaël Ramé for providing ovaries from the slaughterhouse and Proof Reading Service company for the English editing of our manuscript.

\section{References}

Altinkaya SO, Nergiz S, Kucuk M \& Yuksel H 2014 Apelin levels are higher in obese patients with endometrial cancer. Journal of Obstetrics and Gynaecology Research 41 294-300. (doi:10.1111/jog.12503)

Bai B, Tang J, Liu H, Chen J, Li Y \& Song W 2008 Apelin-13 induces ERK1/2 but not p38 MAPK activation through coupling of the human apelin receptor to the Gi2 pathway. Acta Biochimica et Biophysica Sinica 40 311-318. (doi:10.1111/j.1745-7270.2008.00403.x)

Bertrand C, Valet P \& Castan-Laurell I 2015 Apelin and energy metabolism. Frontiers in Physiology 6 115. (doi:10.3389/fphys.2015.00115)

Bilodeau-Goeseels S, Sasseville M, Guillemette C \& Richard FJ 2007 Effects of adenosine monophosphate-activated kinase activators on bovine oocyte nuclear maturation in vitro. Molecular Reproduction and Development 74 1021-1034. (doi:10.1002/mrd.20574)

Borman SM, Chaffin CL, Schwinof KM, Stouffer RL \& Zelinski-Wooten MB 2004 Progesterone promotes oocyte maturation, but not ovulation, in nonhuman primate follicles without a gonadotropin surge. Biology of Reproduction 71 366-373. (doi:10.1095/biolreprod.103.023390)

Canepa S, Laine A, Bluteau A, Fagu C, Flon C \& Monniaux D 2008 Validation d'une methode immunoenzymatique pour le dosage de la progesterone dans le plasma des ovins et des bovins. Les Cahiers Techniques de L'INRA 64 19-30.

Cekmez F, Cekmez Y, Pirgon O, Canpolat FE, Aydinoz S, Metin Ipcioglu O \& Karademir F 2011 Evaluation of new adipocytokines and insulin resistance in adolescents with polycystic ovary syndrome. European Cytokine Network 22 32-37. (doi:10.1684/ecn.2011.0279)

Chang CY, Tsai YC, Lee CH, Chan TF, Wang SH \& Su JH 2011 Lower serum apelin levels in women with polycystic ovary syndrome. Fertility and Sterility 95 2520-2523.e2521-2522. (doi:10.1016/j. fertnstert.2011.04.044)

Dray C, Knauf C, Daviaud D, Waget A, Boucher J, Buleon M, Cani PD, Attane C, Guigne C, Carpene C et al. 2008 Apelin stimulates glucose utilization in normal and obese insulin-resistant mice. Cell Metabolism 8 437-445. (doi:10.1016/j.cmet.2008.10.003)

Dupont J, Dunn SE, Barrett JC \& LeRoith D 2003 Microarray analysis and identification of novel molecules involved in insulin-like growth factor-1 receptor signaling and gene expression. Recent Progress in Hormone Research Journal 58 325-342. (doi:10.1210/rp.58.1.325)
Fissore RA, He CL \& Vande Woude GF 1996 Potential role of mitogenactivated protein kinase during meiosis resumption in bovine oocytes. Biology of Reproduction 55 1261-1270. (doi:10.1095/ biolreprod55.6.1261)

Goren K, Sagsoz N, Noyan V, Yucel A, Caglayan O \& Bostanci MS 2012 Plasma apelin levels in patients with polycystic ovary syndrome. Journal of the Turkish German Gynecological Association 13 27-31. (doi:10.5152/jtgga.2011.74)

Gutiérrez CG, Campbell BK \& Webb R 1997 Development of a longterm bovine granulosa cell culture system: induction and maintenance of estradiol production, response to follicle-stimulating hormone, and morphological characteristics. Biology of Reproduction 56 608-616.

Habata Y, Fujii R, Hosoya M, Fukusumi S, Kawamata Y, Hinuma S, Kitada C, Nishizawa N, Murosaki S, Kurokawa T et al. 1999 Apelin, the natural ligand of the orphan receptor APJ, is abundantly secreted in the colostrum. Biochimica et Biophysica Acta 1452 25-35. (doi:10.1016/ S0167-4889(99)00114-7)

Hosoya M, Kawamata Y, Fukusumi S, Fujii R, Habata Y, Hinuma S, Kitada C, Honda S, Kurokawa T \& Onda H et al. 2000 Molecular and functional characteristics of APJ. Tissue distribution of mRNA and interaction with the endogenous ligand apelin. Journal of Biological Chemistry 275 21061-21067. (doi:10.1074/jbc.M908417199)

Kawamata Y, Habata Y, Fukusumi S, Hosoya M, Fujii R, Hinuma S, Nishizawa N, Kitada C, Onda H, Nishimura O et al. 2001 Molecular properties of apelin: tissue distribution and receptor binding. Biochimica et Biophysica Acta 1538 162-171. (doi:10.1016/S01674889(00)00143-9)

Liu QF, Yu HW, Sun LL, You L, Tao GZ \& Qu BZ 2015 Apelin-13 upregulates Egr-1 expression in rat vascular smooth muscle cells through the PI3K/ Akt and PKC signaling pathways. Biochemical and Biophysical Research Communications 468 617-621. (doi:10.1016/j.bbrc.2015.10.171)

Lv SY, Yang YJ, Qin YJ, Mo JR, Wang NB, Wang YJ \& Chen Q 2012 Central apelin-13 inhibits food intake via the CRF receptor in mice. Peptides 33 132-138. (doi:10.1016/j.peptides.2011.11.011)

Magnusson C, Billig H, Eneroth P, Roos P \& Hillensjo T 1982 Comparison between the progestin secretion responsiveness to gonadotrophins of rat cumulus and mural granulosa cells in vitro. Acta Endocrinologica 101 611-616.

Maillard V, Uzbekova S, Guignot F, Perreau C, Rame C, CoyralCastel S \& Dupont J 2010 Effect of adiponectin on bovine granulosa cell steroidogenesis, oocyte maturation and embryo development. Reproductive Biology and Endocrinology 8 23. (doi:10.1186/14777827-8-23)

Newson MJ, Pope GR, Roberts EM, Lolait SJ \& O'Carroll AM 2013 Stress-dependent and gender-specific neuroregulatory roles of the apelin receptor in the hypothalamic-pituitary-adrenal axis response to acute stress. Journal of Endocrinological Investigation 216 99-109. (doi:10.1530/JOE-12-0375)

O'Carroll AM, Lolait SJ, Harris LE \& Pope GR 2013 The apelin receptor APJ: journey from an orphan to a multifaceted regulator of homeostasis. Journal of Endocrinological Investigation 219 R13-R35.

O'Dowd BF, Heiber M, Chan A, Heng HH, Tsui LC, Kennedy JL, Shi X, Petronis A, George SR \& Nguyen T 1993 A human gene that shows identity with the gene encoding the angiotensin receptor is located on chromosome 11. Gene 136 355-360.

Peng X, Li F, Wang P, Jia S, Sun L \& Huo H 2015 Apelin-13 induces MCF-7 cell proliferation and invasion via phosphorylation of ERK1/2. International Journal of Molecular Medicine 36 733-738. (doi:10.3892/ ijmm.2015.2265)

Reverchon M, Bertoldo MJ, Rame C, Froment P \& Dupont J 2014 CHEMERIN (RARRES2) decreases in vitro granulosa cell steroidogenesis and blocks oocyte meiotic progression in bovine species. Biology of Reproduction 90102.

Reverchon M, Rame C, Bunel A, Chen W, Froment P \& Dupont J 2016 VISFATIN (NAMPT) improves in vitro IGF1-induced steroidogenesis and IGF1 receptor signaling through SIRT1 in bovine granulosa cells. Biology of Reproduction 94 54. (doi:10.1095/biolreprod.113.117044)

Roche J, Ramé C, Reverchon M, Mellouk N, Cornuau M, Guerif F, Froment P \& Dupont J 2016 Apelin (APLN) and apelin receptor (APLNR) in human ovary: expression, signaling and regulation of steroidogenesis in primary human luteinized granulosa cells. Biology of Reproduction 95 104. (doi:10.1095/biolreprod.116.141754) 
Sandal S, Tekin S, Seker FB, Beytur A, Vardi N, Colak C, Tapan T, Yildiz S \& Yilmaz B 2015 The effects of intracerebroventricular infusion of apelin-13 on reproductive function in male rats. Neuroscience Letters 602 133-138. (doi:10.1016/j.neulet.2015.06.059)

Schilffarth S, Antoni B, Schams D, Meyer HH \& Berisha B 2009 The expression of apelin and its receptor APJ during different physiological stages in the bovine ovary. International Journal of Biological Sciences $\mathbf{5}$ 344-350. (doi:10.7150/ijbs.5.344)

Shimizu T, Kosaka N, Murayama C, Tetsuka M \& Miyamoto A 2009 Apelin and APJ receptor expression in granulosa and theca cells during different stages of follicular development in the bovine ovary: involvement of apoptosis and hormonal regulation. Animal Reproduction Science $\mathbf{1 1 6}$ 28-37. (doi:10.1016/j.anireprosci.2009.01.009)

Shirasuna K, Shimizu T, Sayama K, Asahi T, Sasaki M, Berisha B, Schams D \& Miyamoto A 2008 Expression and localization of apelin and its receptor APJ in the bovine corpus luteum during the estrous cycle and prostaglandin F2alpha-induced luteolysis. Reproduction 135 519-525. (doi:10.1530/REP-07-0409)

Shuang L, Jidong W, Hongjuan P \& Zhenwei Y 2016 Effects of apelin on proliferation and apoptosis in rat ovarian granulosa cells. Clinical and Experimental Obstetrics and Gynecology 43 409-413.

Silva JR, Figueiredo JR \& van den Hurk R 2009 Involvement of growth hormone $(\mathrm{GH})$ and insulin-like growth factor (IGF) system in ovarian folliculogenesis. Theriogenology 71 1193-1208. (doi:10.1016/j. theriogenology.2008.12.015)

Sun X, Wu X, Zhou Y, Yu X \& Zhang W 2015 Evaluation of apelin and insulin resistance in patients with PCOS and therapeutic effect of drospirenone-ethinylestradiol plus metformin. Medical Science Monitor 21 2547-2552. (doi:10.12659/MSM.894926)

Tatemoto K, Hosoya M, Habata Y, Fujii R, Kakegawa T, Zou MX, Kawamata Y, Fukusumi S, Hinuma S, Kitada C et al. 1998 Isolation and characterization of a novel endogenous peptide ligand for the human APJ receptor. Biochemical and Biophysical Research Communications 251 471-476. (doi:10.1006/bbrc.1998.9489)

Tekin S, Erden Y, Sandal S, Etem Onalan E, Ozyalin F, Ozen H \& Yilmaz B 2016 Effects of apelin on reproductive functions: relationship with feeding behavior and energy metabolism. Archives of Physiology and Biochemistry 123 9-15. (doi:10.1080/13813455.2016.1211709)

Tosca L, Froment P, Solnais P, Ferre P, Foufelle F \& Dupont J 2005 Adenosine 5'-monophosphate-activated protein kinase regulates progesterone secretion in rat granulosa cells. Endocrinology $\mathbf{1 4 6}$ 4500-4513. (doi:10.1210/en.2005-0301)
Tosca L, Chabrolle C, Uzbekova S \& Dupont J 2007a Effects of metformin on bovine granulosa cells steroidogenesis: possible involvement of adenosine 5' monophosphate-activated protein kinase (AMPK). Biology of Reproduction 76 368-378. (doi:10.1095/biolreprod.106.055749)

Tosca L, Uzbekova S, Chabrolle C \& Dupont J 2007 b Possible role of 5'AMPactivated protein kinase in the metformin-mediated arrest of bovine oocytes at the germinal vesicle stage during in vitro maturation. Biology of Reproduction 77 452-465. (doi:10.1095/biolreprod.107.060848)

Wu D, He L \& Chen L 2014 Apelin/APJ system: a promising therapy target for hypertension. Molecular Biology Reports 41 6691-6703. (doi:10.1007/s11033-014-3552-4)

Yang L, Su T, Lv D, Xie F, Liu W, Cao J, Sheikh IA, Qin X, Li L \& Chen L 2014 ERK1/2 mediates lung adenocarcinoma cell proliferation and autophagy induced by apelin-13. Acta Biochimica et Biophysica Sinica 46 100-111. (doi:10.1093/abbs/gmt140)

Yang Y, Zhang XJ, Li LT, Cui HY, Zhang C, Zhu CH \& Miao JY 2016 Apelin-13 protects against apoptosis by activating AMP-activated protein kinase pathway in ischemia stroke. Peptides 75 96-100. (doi:10.1016/j. peptides.2015.11.002)

Yue P, Jin H, Aillaud M, Deng AC, Azuma J, Asagami T, Kundu RK, Reaven GM, Quertermous T \& Tsao PS 2010 Apelin is necessary for the maintenance of insulin sensitivity. American Journal of Physiology: Endocrinology and Metabolism 298 E59-E67. (doi:10.1152/ajpendo. 00385.2009)

Zhang X \& Armstrong DT 1989 Effects of follicle-stimulating hormone and ovarian steroids during in vitro meiotic maturation on fertilization of rat oocytes. Gamete Research 23 267-277. (doi:10.1002/mrd.1120230304)

Zhang L, Takara K, Yamakawa D, Kidoya H \& Takakura N 2016 Apelin as a marker for monitoring the tumor vessel normalization window during antiangiogenic therapy. Cancer Science 107 36-44. (doi:10.1111/ cas.12836)

Received 5 September 2016

First decision 3 October 2016

Revised manuscript received 14 February 2017

Accepted 28 February 2017 